\title{
Experimental Investigation of a Novel Membrane-based Condensing Heat Exchanger for High Efficiency Furnaces
}

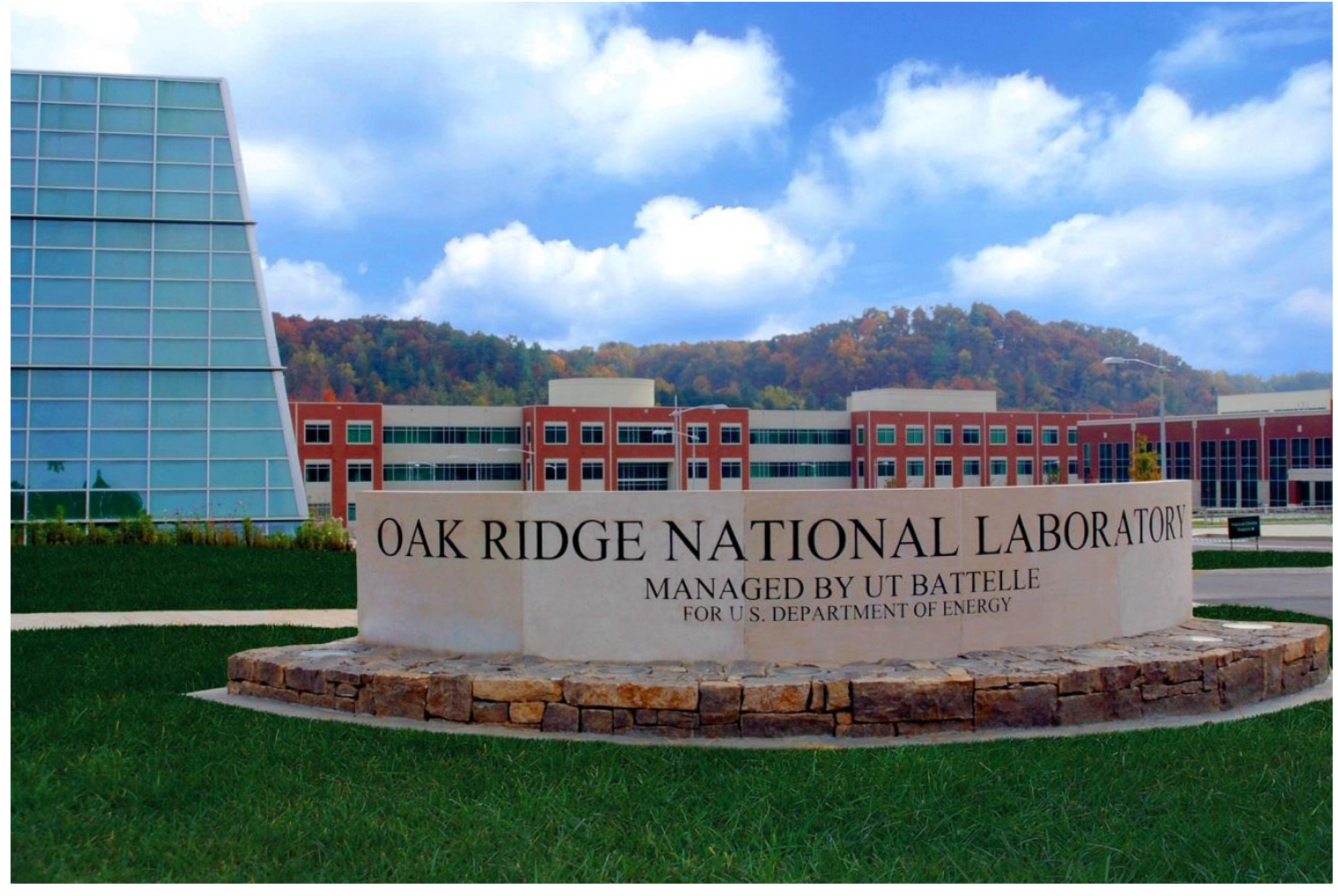

Lingshi Wang Brian Bischoff Aimee Church James Klett Anthony Gehl Xiaobing Liu Van Baxter

November 2021 


\title{
DOCUMENT AVAILABILITY
}

Reports produced after January 1, 1996, are generally available free via US Department of Energy (DOE) SciTech Connect.

Website www.osti.gov

Reports produced before January 1, 1996, may be purchased by members of the public from the following source:

\author{
National Technical Information Service \\ 5285 Port Royal Road \\ Springfield, VA 22161 \\ Telephone 703-605-6000 (1-800-553-6847) \\ TDD 703-487-4639 \\ Fax 703-605-6900 \\ E-mail info@ntis.gov \\ Website http://classic.ntis.gov/
}

Reports are available to DOE employees, DOE contractors, Energy Technology Data Exchange representatives, and International Nuclear Information System representatives from the following source:

Office of Scientific and Technical Information

PO Box 62

Oak Ridge, TN 37831

Telephone 865-576-8401

Fax 865-576-5728

E-mail reports@osti.gov

Website https://www.osti.gov/

This report was prepared as an account of work sponsored by an agency of the United States Government. Neither the United States Government nor any agency thereof, nor any of their employees, makes any warranty, express or implied, or assumes any legal liability or responsibility for the accuracy, completeness, or usefulness of any information, apparatus, product, or process disclosed, or represents that its use would not infringe privately owned rights. Reference herein to any specific commercial product, process, or service by trade name, trademark, manufacturer, or otherwise, does not necessarily constitute or imply its endorsement, recommendation, or favoring by the United States Government or any agency thereof. The views and opinions of authors expressed herein do not necessarily state or reflect those of the United States Government or any agency thereof. 
Buildings and Transportation Science Division

\title{
EXPERIMENTAL INVESTIGATION OF A NOVEL MEMBRANE-BASED CONDENSING HEAT EXCHANGER FOR HIGH EFFICIENCY FURNACES
}

\author{
Lingshi Wang \\ Brian Bischoff \\ Aimee Church \\ James Klett \\ Anthony Gehl \\ Xiaobing Liu \\ Van Baxter
}

November 2021

Prepared by

OAK RIDGE NATIONAL LABORATORY

Oak Ridge, TN 37831-6283

managed by

UT-BATTELLE LLC

for the

US DEPARTMENT OF ENERGY

under contract DE-AC05-00OR22725 



\section{CONTENTS}

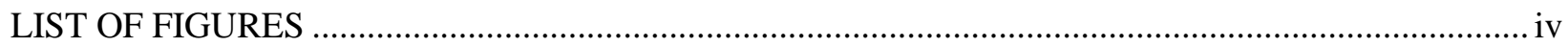

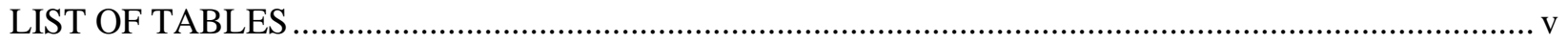

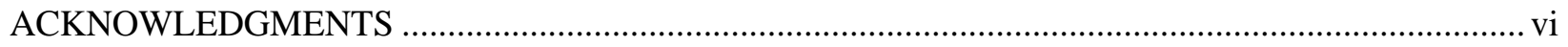

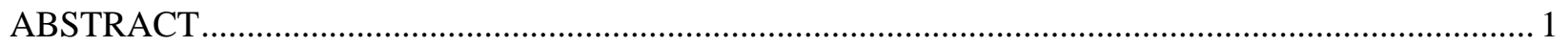

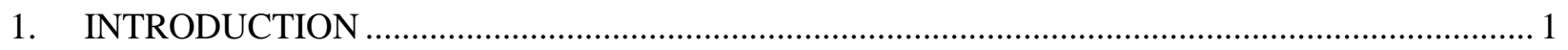

2. PRINCIPLE OF SEPARATION OF WATER VAPOR BY CAPILLARY CONDENSATION ......... 3

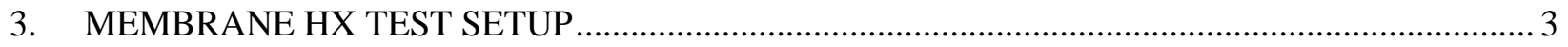

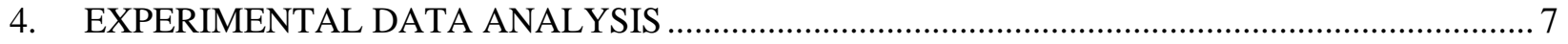

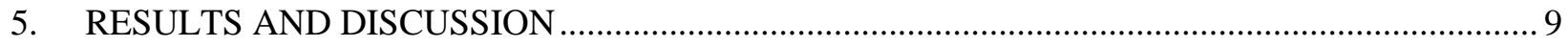

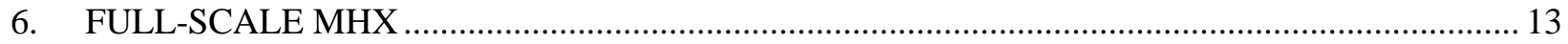

7. MHX VALUE PROPOSITION AND INSTALLED COST REDUCTION POTENTIAL ................ 21

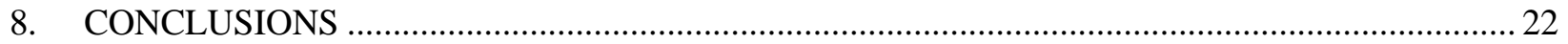

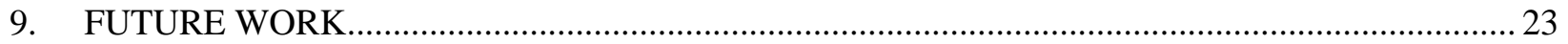

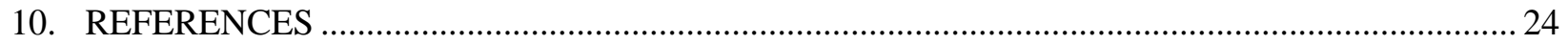

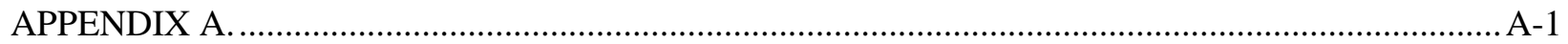

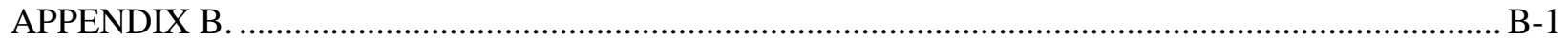

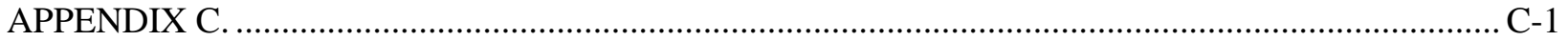




\section{LIST OF FIGURES}

Figure 1. Common issues when replacing a noncondensing furnace with a condensing furnace. .............. 2

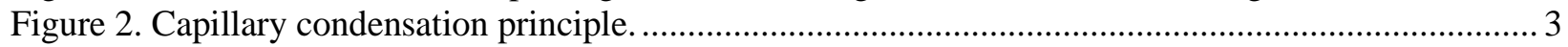

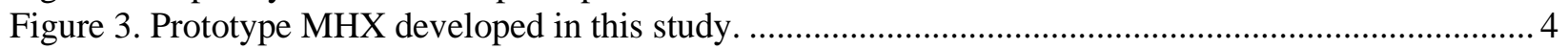

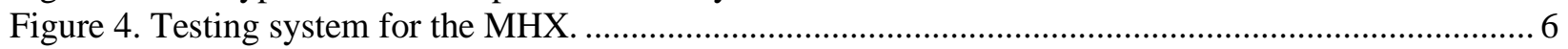

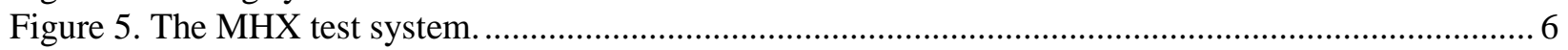

Figure 6. Latent heat recovered by the single-membrane MHX as a function of flue gas flow rate

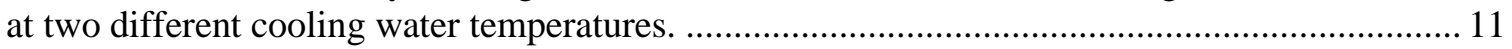

Figure 7. Relationship between the percentage of recovered latent heat and the flue gas flow rate in a single-membrane MHX

Figure 8. Relationship between MHX exit temperature and the flue gas flow rate in a single MHX.

Figure 9. $\mathrm{pH}$ values of the MHX condensate and the water condensed in the reject stream under various coolant temperatures and flue gas flow rates in a single MHX

Figure 10. A cross-section of an MHX module with nine channels or membranes in a cylindrical CGF monolith in which the interior surface of each channel is coated with a nanoporous coating.

Figure 11. A rendering a cylindrical CGF MHX module with multiple channels.................................. 14

Figure 12. A rendering of an oval-shaped MHX module of CGF with multiple channels....................... 15

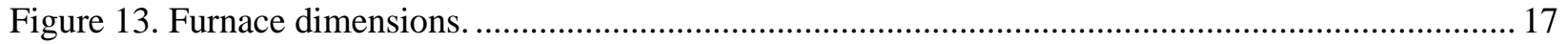

Figure 14. Furnace efficiency as a function of flue gas flow............................................................... 18

Figure 15. Furnace efficiency as a function of MHX membrane monolith diameter. ............................. 18

Figure 16. Furnace efficiency as a function of MHX exit temperature. ............................................... 19

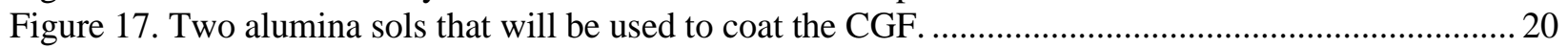

Figure 18. Acid treatment on CGF to increase hydrophilicity of the graphite surface. ............................. 20 


\section{LIST OF TABLES}

Table 1. Specifications of the measurement instrumentation 7

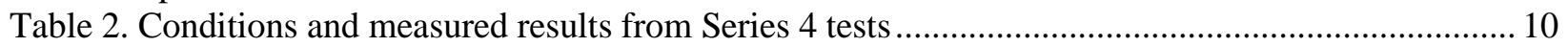

Table 3. Summary of Series 4 conditions and extrapolation to a full-sized $80,000 \mathrm{Btu} / \mathrm{h}$ gas input furnace ....

Table 4. Average 2012 consumer purchase price for residential furnaces, 2013 dollars (from DOE 2015)

Table 5. Average total installed cost for residential furnaces, 2013 dollars (from DOE 2015).....

Table 6. Additional installation costs for nonweatherized gas furnaces in replacement applications, 2013 dollars (from DOE 2015) 


\section{ACKNOWLEDGMENTS}

The authors gratefully acknowledge Jeff Munk, Stephen Kowalski, and Kyle Gluesenkamp for their many helpful suggestions and critical technical reviews of this document during its preparation. This work was funded by the Emerging Technologies Program of the Buildings Technologies Office at the US Department of Energy under contract DE-AC05-00OR22725 with UT-Battelle, LLC. This work has been authored by staff of UT-Battelle, LLC, under contract DE-AC05-00OR22725 with the US Department of Energy (DOE). The US government retains and the publisher, by accepting the presentation for publication, acknowledges that the US government retains a nonexclusive, paid-up, irrevocable, worldwide license to publish or reproduce the published form of this presentation, or allow others to do so, for US government purposes. DOE will provide public access to these results of federally sponsored research in accordance with the DOE Public Access Plan (http://energy.gov/downloads/doe-publicaccess-plan). 


\begin{abstract}
Building space heating consumes approximately one-third of all global natural gas end use. Higherefficiency (i.e., condensing) furnaces constitute only about $40 \%$ of the annual furnace shipments in the United States, because the condensing heat exchangers must use expensive, corrosion-resistant materials to protect from acidic components in the furnace flue gas stream. Increasing the market share of highefficiency furnaces will reduce greenhouse gas emissions. This study developed and tested a benchtop prototype of a novel membrane-based heat exchanger (MHX) for high-efficiency furnaces to achieve nonacidic condensation via nanoporous membranes.
\end{abstract}

Test results show that both sensible and latent heat were recovered by the MHX, and the fraction of latent heat recovery ranged from about $25 \%$ to $45 \%$ over the range of operating conditions evaluated. The amount of water condensed through the MHX increased with the increase of flue gas flow rate and decreased with increasing coolant temperature. The fraction of latent heat recovery decreased with the increase of flue gas flow rate and coolant temperature. The $\mathrm{pH}$ value of condensed water from the MHX was only mildly acidic, varying from 5.3 to 5.6 without any additional treatment, about 2.0 to $2.3 \mathrm{pH}$ points higher (i.e., less acidic) than typical values for the condensate from conventional condensing furnaces. Therefore, feasibility of the MHX was experimentally verified, and the MHX could enable wider market penetration of highly energy-efficient condensing furnaces by reducing costs associated with managing the acid condensation compared with conventional condensing furnaces, possibly enabling the use of existing vent systems when replacing noncondensing furnaces (due to higher flue gas exit temperatures), and possibly reducing furnace first costs.

Keywords: membrane-based condensing heat exchanger, capillary condensation, furnace, experimental investigation, annual fuel utilization efficiency

\title{
1. INTRODUCTION
}

Building equipment efficiency plays an important role in reducing primary energy consumption. According to the most recent US Energy Information Administration (EIA) estimates, residential and commercial buildings will consume 38.22 quads, or $37.6 \%$, of the total US primary energy consumption in 2030 (EIA 2017), continuing to exceed industrial and transportation energy consumption. Natural gas consumption for building space heating alone is 4.47 quads (EIA 2017). Natural gas consumption releases tremendous amounts of greenhouse gas emissions and is a significant contributor to climate change. The two main types of furnaces on the market are condensing, or high-efficiency, and noncondensing types. Condensing furnaces are available with annual fuel utilization efficiency (AFUE) ratings ranging from about $90 \%$ to $98 \%$ compared with noncondensing models, which have maximum AFUE ratings of approximately $80 \%-82 \%$. Combustion products in the condensing furnace include $\mathrm{CO}_{2}$, water, excess air, and small amounts of acid gases. Condensation of water from flue gases occurs in a secondary heat exchanger (HX) as the temperature is lowered below the dew point. This condensation is the primary contributor to increased efficiency for condensing furnaces. When this condensation occurs, the acid gases also dissolve in the condensed water, which acidifies the condensate. To avoid corrosion issues, more expensive stainless steel alloys are required for the secondary HX (Lutz et al. 2006). Furthermore, the acidic condensate drainage requires a neutralizing salt system to treat the condensate. If an existing noncondensing furnace is replaced by a condensing furnace, the existing venting system typically also requires replacement because of the acidity issue and the lower flue gas temperatures typical of condensing furnaces (Figure 1). Furthermore, current high-efficiency condensing furnaces typically operate with positive pressure, airtight vents. Noncondensing furnace vents generally operate at negative pressure, relying on buoyancy driven flow, and are not airtight. These drawbacks cause condensing furnace retrofit installation costs to be higher than those of direct replacement noncondensing models and 
inhibit their market penetration. High-efficiency (i.e., condensing) furnaces accounted for only approximately $40 \%$ of the total US market in 2020 (Energy Star, 2020). Despite their lower AFUE, noncondensing furnaces are more commonly used in the United States than condensing furnaces because they are less expensive.

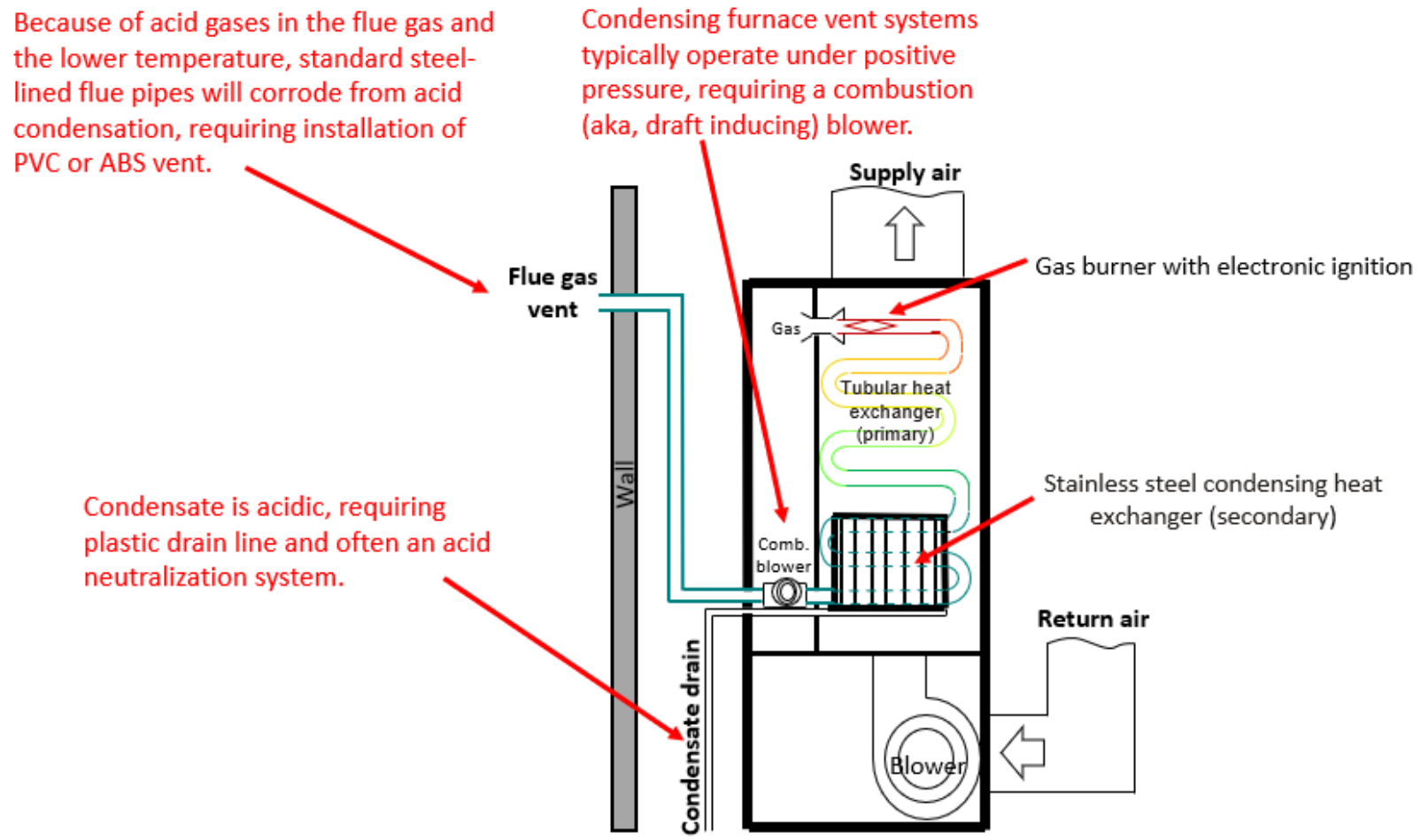

Figure 1. Common issues when replacing a noncondensing furnace with a condensing furnace.

This project investigated a novel technology that can provide an AFUE level similar to that of conventional condensing furnaces but without creating acidic condensate and enabling higher flue gas temperatures (similar to those of noncondensing furnaces), which could yield lower installation costs. If this technology could enable the production of a condensing furnace with lower installed cost than conventional technology, then the market share of condensing furnaces could increase. Replacing all noncondensing furnaces (80\% AFUE) with the new technology condensing furnaces (with 95\% AFUE) could yield annual energy savings of about 0.51 quads.

This project began in FY 2018 with the goal of demonstrating a system that employs a conductive inorganic membrane to condense water from the flue gas in its pores. This conductive membrane can transfer both the sensible heat of the flue gas and the latent heat of the condensed water to the air being conditioned. Advanced inorganic membranes developed at the US Department of Energy's (DOE's) Oak Ridge National Laboratory (ORNL) (Hu et al. 2016; Hu et al. 2019) were applied to achieve high-AFUE furnace performance by recovering latent heat (e.g., the heat of condensation of the water vapor) from high-temperature flue gases of a conventional noncondensing furnace. A thermally conductive inorganic membrane was used to condense water from the flue gas by capillary condensation in the pores of the membrane. Compared with the water that condenses on the surface of a conventional condensing HX, the water that is condensed in the pores is much less acidic, according to previous unpublished studies that were the basis for US Patent 8,511,072 (Judkins et al. 2013). A bench-scale membrane-based condensing HX was developed and tested using a flue gas stream from a conventional noncondensing furnace. A parametric study was also conducted to investigate the influence of operating conditions on the performance of this membrane-based condensing HX. 


\section{PRINCIPLE OF SEPARATION OF WATER VAPOR BY CAPILLARY CONDENSATION}

Water separation from furnace flue gas by the membrane-based HX involves capillary condensation. The nanoporous membranes have pores in the range of 5 to $20 \mathrm{~nm}$ and can separate gases using capillary condensation (Gregg and Sing 1982). Capillary condensation occurs via a process in which the vapors first adsorb onto the surface of a micropore. As the concentration of vapors increases, multilayer adsorption takes place until the surface tension causes the pores to completely fill with liquid. These surface tension forces are higher in smaller pores and cause a concave meniscus at the interface between the liquid and vapor, as shown in Figure 2. This concave meniscus lowers the vapor pressure above the liquid in the pores with the relationship defined by the Kelvin equation, Eq. (1).

$$
\ln \left(\frac{P}{P_{s a t}}\right)=\frac{-2 \gamma V_{m}}{r_{k} R T}
$$

where $P / P_{\text {sat }}$ is the ratio of the vapor pressure to the saturation vapor pressure, $\gamma$ is the surface tension of the fluid, $V_{m}$ is the molar volume of the fluid, and $r_{k}$ is the Kelvin radius $\left(r_{k}=\right.$ pore radius - adsorbed thickness).

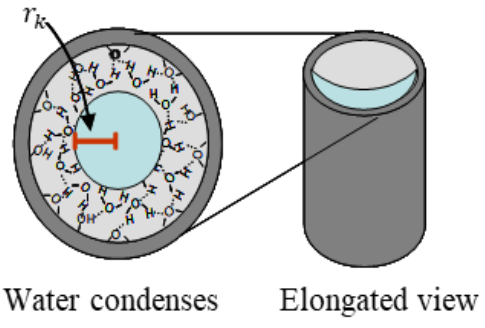

a

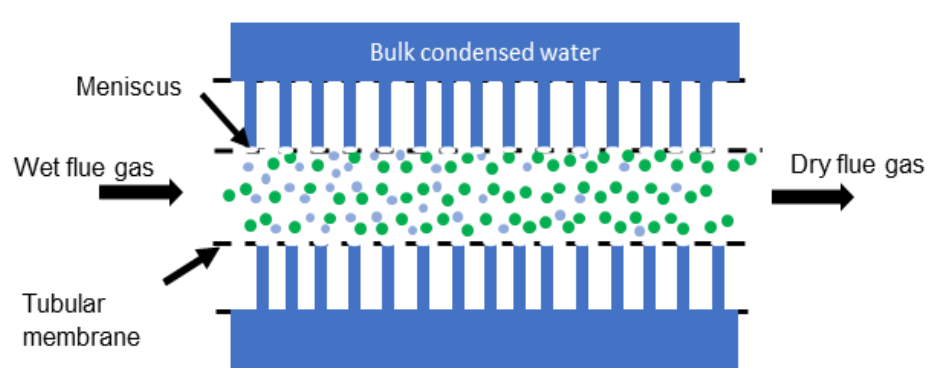

b

Figure 2. Capillary condensation principle. The concave meniscus (a) and condensation through the membrane (b).

In capillary condensation, separation occurs when one constituent condenses in the pores and blocks transport of the other noncondensable gases. In this study, the membrane was designed to condense the water produced from the combustion of natural gas while blocking the remaining flue gases, such as oxygen, nitrogen, $\mathrm{CO}_{2}$, and the acid gases $\mathrm{SO}_{x}$ and $\mathrm{NO}_{x}$. Heat is released during this condensation process and is recovered by the membrane. Because this condensation occurs at a higher temperature than conventional condensation, and it occurs within the pores and not in the bulk, condensation and recovery of latent energy can occur without lowering the flue gas stream temperature as much as with a conventional condensing HX.

\section{MEMBRANE HX TEST SETUP}

The prototype bench-scale membrane HX (MHX) used in this project is constructed from a tubular metallic-based nanoporous membrane and a custom double-walled holder, as shown in Figure 3. This double-walled holder serves two functions: the inner shell houses the tubular membrane and collects the condensed water, and the outer shell cools the MHX. Chilled water flowed through the outer shell to cool the MHX and collect both the sensible and latent heat from the membrane. Figure 3 shows the nanoporous tubular membrane in the lower left. In the upper left, the membrane is wrapped in porous conductive graphite foam (CGF). The photo in the upper right shows the components of the MHX, including the membrane connected to stainless steel tubing using Swagelok connectors and Teflon 
ferrules, the double-walled aluminum shell, and the sanitary end fittings with bored-through Swagelok fittings. To assemble the MHX, the membrane with tubing extensions was wrapped in a CGF material and inserted in the shell. Then, the sanitary end fittings were slid over the tubing extensions before being clamped to the shell using the appropriate gaskets. The schematic at the center shows how the flue gas enters the MHX, water vapor is condensed in the membrane, and the drier flue gas exits the MHX. The outer cooling shell was omitted for clarity.

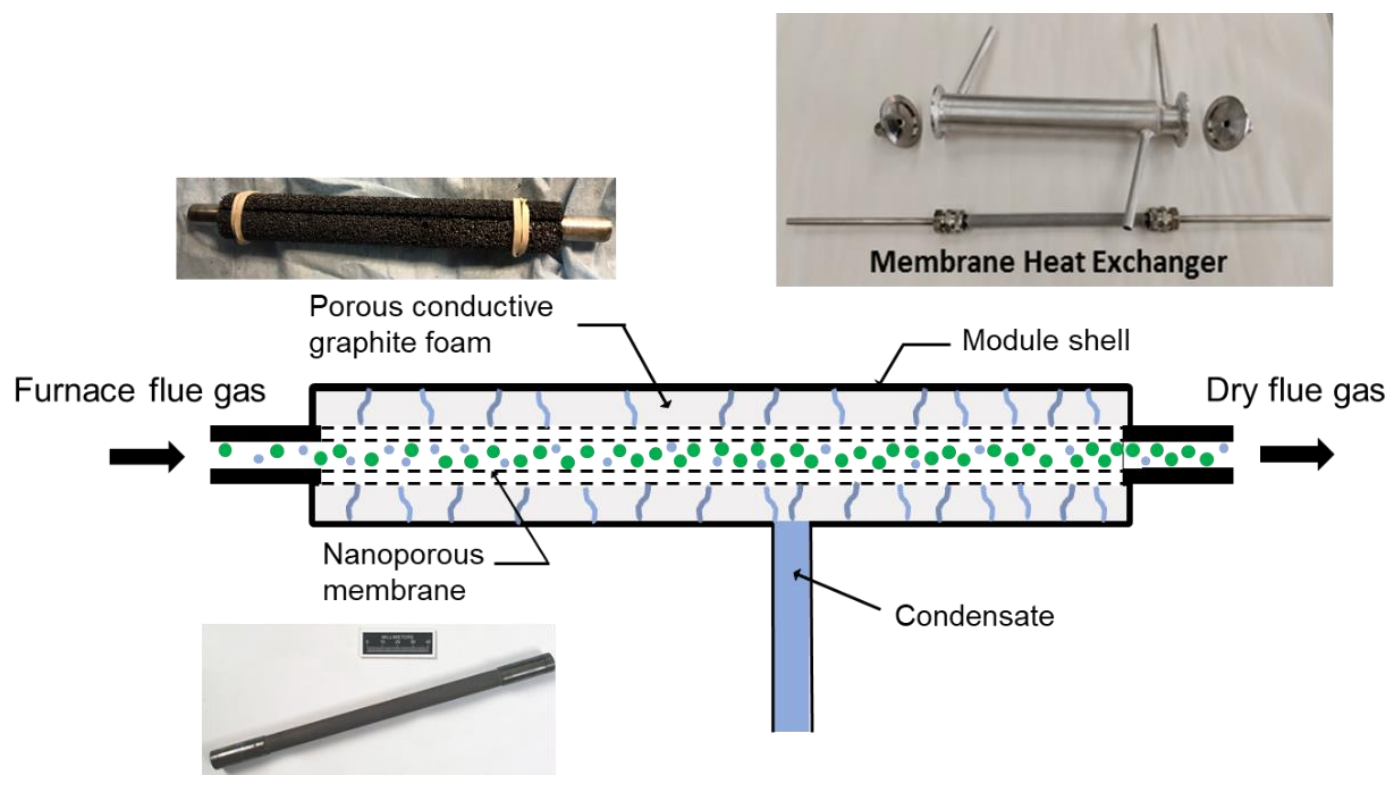

Figure 3. Prototype MHX developed in this study.

The membranes employed in this project were fabricated under controlled conditions. Support tubes were formed from stainless steel (Type 434) by extrusion and sintered at $1,050^{\circ} \mathrm{C}$ under a hydrogen atmosphere for $1 \mathrm{~h}$ to produce the support structure. The tubes were trimmed, and nonporous $0.5 \mathrm{in}$. diameter end fittings were welded on each end to seal the tubular membranes into the holder using standard Swagelok fittings. The porous support tubes had an average diameter of $11.2 \mathrm{~mm}$ and a wall thickness of $0.51 \mathrm{~mm}$ with an average pore diameter of $4.18 \mu \mathrm{m}$. A thin layer of gamma aluminum oxide was then applied to the inside surface of the support tube, and the layer was heat-treated at $950^{\circ} \mathrm{C}$ to sinter the particles into a matrix and adjust the pore size forming the nanoporous membrane layer. The tubes were characterized for leaks using a standard isopropanol bubble test for air permeance at $1 \mathrm{~atm}$, and a flow-weighted pore size determination was completed to confirm a median pore diameter of approximately $8 \mathrm{~nm}$. The nanoporous gamma alumina layer, hydrophilic in nature, served as the functional element in the capillary condensation process, condensing the water from the flue gas. The resulting heat of condensation is transferred through the support tube to the outer membrane shell.

The inner shell of the membrane holder collected the water condensed by the membrane from the flue gas. The outer shell contained flowing cooling water (simulating the conditioned air of a residential gas furnace) to control the condensation temperature and recover the heat released by the condensation process (latent heat) and from the cooling of the flue gas (sensible heat). The aluminum holder increased heat conduction and used sanitary flanges to seal the inner collection shell. The holder has three ports. One port connects to the inner shell to collect the condensed water, and the other two carry the cooling water in and out of the outer shell. Prior to inserting the membrane, the membrane was wrapped in a clamshell made of porous CGF. This foam contacted many points on the support side of the membrane and the inner surface of the collection shell to transfer the heat directly from the membrane to the cooling shell. The membrane assembly was completed by connecting the flue gas lines to the tubular membrane 
using Teflon Swagelok ferrules to minimize heat conduction from the membrane to the flue gas lines. The membrane assembly was also sealed into the sanitary flanges using Teflon ferrules to minimize heat transfer from the flue gas lines to the membrane shell.

An experimental apparatus was developed to test the performance of the prototype MHX. The test loop design evolved throughout the project. A history of the loop design changes along with the rationale for each is described in Appendix A. To summarize the system design history, the first iteration planned to use a chilled mirror dew point sensor to measure the moisture content in the flue gas. Initial tests demonstrated that the chilled mirror device was not well suited for the very high moisture content of the flue gas, and the acid gases corroded the mirror, therefore its use was discontinued. Early tests also showed very good performance even at the highest flue gas flow rate achievable given the piping diameter and small flue gas pump used; therefore, a larger pump was installed, and the flue gas tubing size diameter was increased to reduce the flue gas pressure drop through the test loop. Another design change was prompted by the discovery of a leak at the inlet side of the flue gas pump, which allowed infiltration of air from the room into the system. This air infiltration created an inaccurate flow measurement because the flowmeter was plumbed after the pump. By relocating the meter upstream of the pump, the flow measurement through the MHX could be accurately determined.

The final test loop system configuration is shown schematically in Figure 4 and a photograph is included in Figure 5. A slipstream sample of the flue gas from a noncondensing gas furnace was diverted to the MHX where the water vapor from the flue gas was condensed by the membrane and the remaining flue gas exited the MHX. Cooling to the MHX was provided by a recirculating refrigerated water bath. A vacuum pump provided sufficient vacuum driving force to extract the condensed water from the MHX (i.e., membrane condensate) without completely emptying the pores of the membrane. The condensate from the membrane was collected in an Erlenmeyer flask that was immersed in an ice bath to reduce reevaporation by the vacuum pump. The partially dried flue gas was then pulled through another Erlenmeyer flask (reject condensate) that was placed in the ice water bath before flowing through a natural gas flowmeter. An air pump provided the needed vacuum to induce flow of the exhausted flue gas from the furnace through the MHX, reject Erlenmeyer flask, and natural gas flowmeter. Flows, temperatures, and other conditions were continuously monitored by a National Instruments data acquisition system using a customized software program written in LabVIEW. The temperature of the flue gas was monitored by thermocouples in four places: leaving the furnace, entering the MHX, exiting the MHX, and above the condensed water in the reject flask. Although typical noncondensing furnace flue gas exhaust is in the range of $175^{\circ} \mathrm{C}$ to $225^{\circ} \mathrm{C}$, the measured temperature of the flue gas in the flue pipe outside of the furnace was approximately $158^{\circ} \mathrm{C}$. For safety and operational reasons, we limited the flue gas stream entering the prototype test MHX to around $148^{\circ} \mathrm{C}$ to $150^{\circ} \mathrm{C}$ Flue gas sample stream temperature was controlled using a series of temperature controllers connected to heat-trace tapes covered by high-temperature insulation to maintain the target entering temperature range and to keep water vapor in the flue gas from condensing in the system piping where it could not be quantified. At low flows, the upper temperature was limited by the amount of heat that could be provided by the heat tapes, and the temperature of the system lines that could be physically contacted by the operator was limited. The lines from the MHX to the reject flask were also heated and insulated to avoid condensation in this section of piping. The temperature of the cooling water going into and out of the MHX was monitored continuously using thermocouples. The chilled water flow rate was monitored using a liquid flowmeter connected to the National Instruments system, and the natural gas flowmeter was connected to a Campbell Scientific data acquisition system. The pressure level at the vacuum pump was monitored with an absolute pressure transducer and the pressure drop across the MHX was monitored using a differential pressure transducer. 


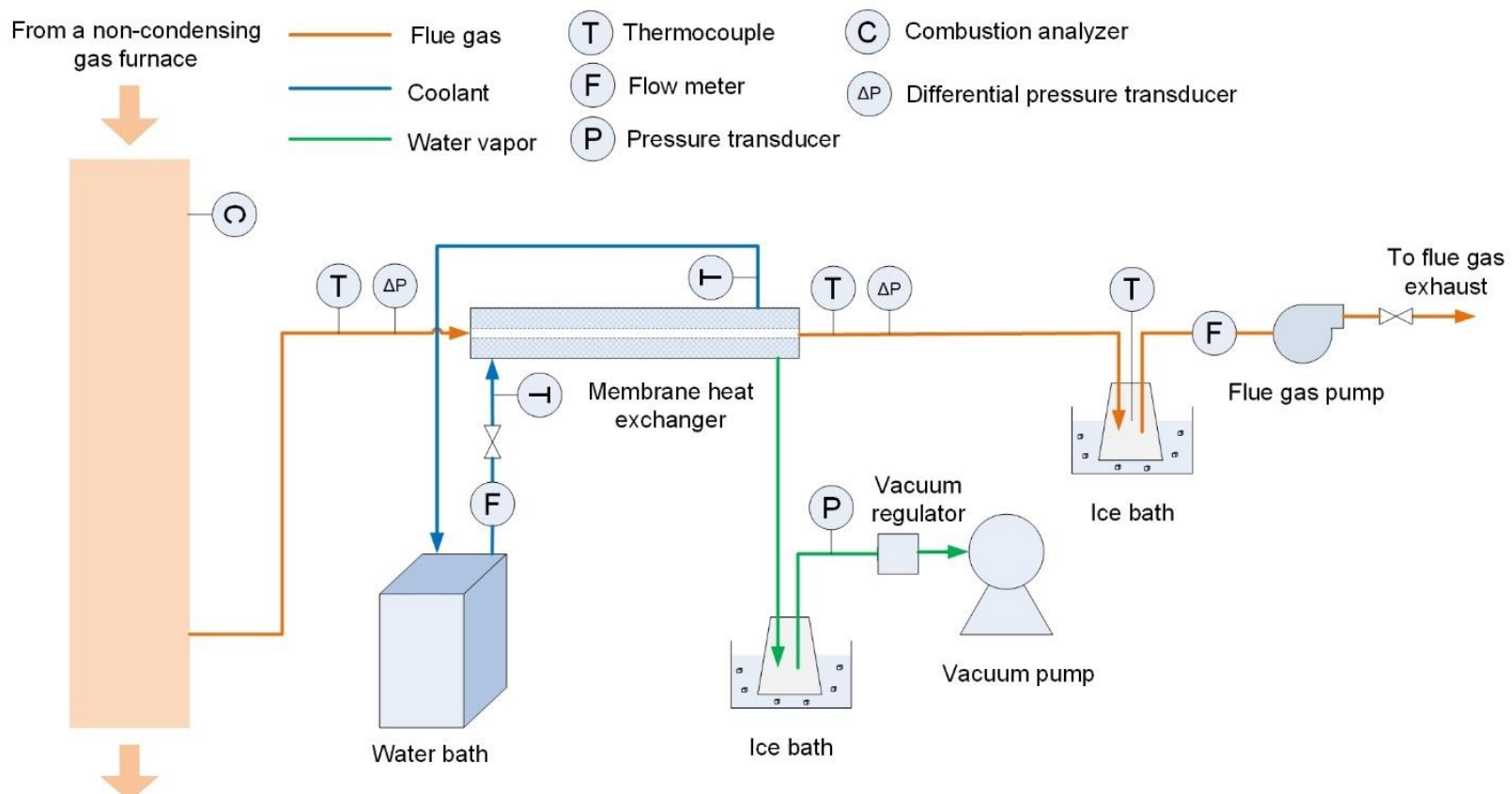

To flue gas exhaust

Figure 4. Testing system for the MHX.

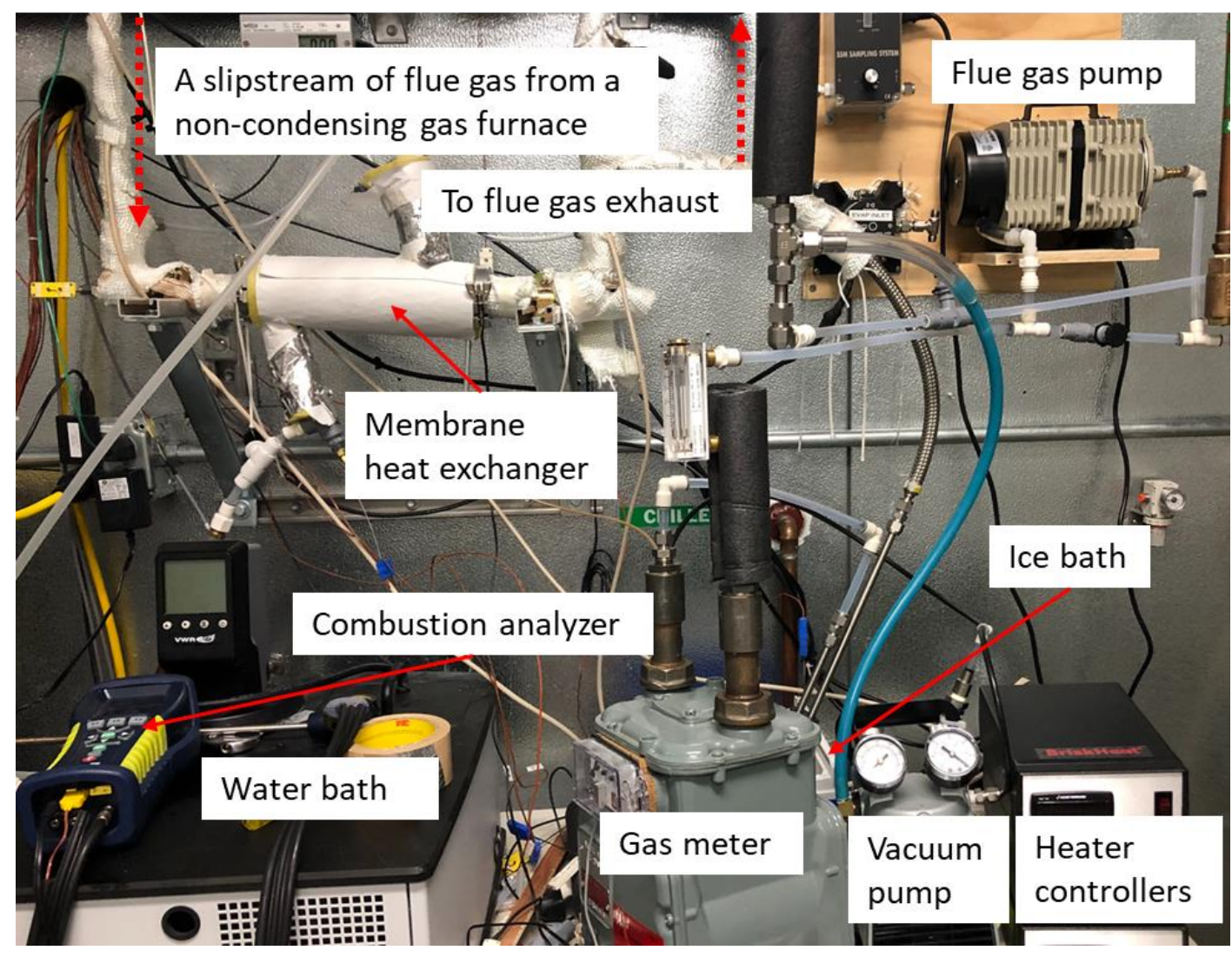

Figure 5. The MHX test system. 
Controlled variables during the tests include flue gas flow rate, MHX inlet temperature, and cooling water temperature. A combustion and emissions analyzer determined the concentration of $\mathrm{CO}_{2}$ in the flue gas, and the water concentration was calculated using stoichiometry. A scale weighed the collected water. A $\mathrm{pH}$ meter measured the $\mathrm{pH}$ value of the collected water. The specifications of the measurement instrumentation are shown in Table 1.

Table 1. Specifications of the measurement instrumentation

\begin{tabular}{|c|c|c|c|}
\hline Measured value & Instrument & $\begin{array}{r}\text { Range } \\
\end{array}$ & Uncertainty \\
\hline Flue gas composition & $\begin{array}{l}\text { PCA } 400 \text { combustion and } \\
\text { emissions analyzer }\end{array}$ & $0 \%-20.9 \%$ for $\mathrm{O}_{2}$ & $\pm 0.3 \% \mathrm{O}_{2}$ \\
\hline Temperature of coolant & $\begin{array}{l}\text { Omega Type T thermocouple } \\
\text { probes }\end{array}$ & $-198^{\circ} \mathrm{C}-371^{\circ} \mathrm{C}$ & $\pm 0.75 \%$ \\
\hline Temperature of flue gas & $\begin{array}{l}\text { Omega Type K thermocouple } \\
\text { probes }\end{array}$ & $-198^{\circ} \mathrm{C}-927^{\circ} \mathrm{C}$ & $\pm 0.4 \%$ \\
\hline Flow rate of flue gas & $\begin{array}{l}\text { AC250 temperature } \\
\text { compensated gas meter }\end{array}$ & $\begin{array}{l}250 \mathrm{SCFH}\left(7.1 \mathrm{~m}^{3} / \mathrm{h}\right)(0.60 \\
\text { specific gravity gas }) \text { at } 0.5 \mathrm{in} . \\
\text { W.C. differential }\end{array}$ & $\begin{array}{l}< \pm 1 \% \text { based on } \\
\text { meter specs } \\
\text { (https://www.ima } \\
\text { csystems.com/AC } \\
\text {-250.pdf) }\end{array}$ \\
\hline Flow rate of coolant & $\begin{array}{l}\text { Omega FTB600B Series } \\
\text { flowmeters, model FTB601B- } \\
\mathrm{T}\end{array}$ & $100-2,000 \mathrm{~mL} / \mathrm{min}$ & $\pm 1 \%$ \\
\hline $\begin{array}{l}\text { PH value of collected } \\
\text { water }\end{array}$ & $\begin{array}{l}\text { Beckman Coulter } 360 \\
\mathrm{pH} / \text { Temp/mV Meter, model } \\
511212\end{array}$ & $0-14$ & $\pm 0.02 \mathrm{pH}$ \\
\hline Weight of collected water & Torbal AG4000 scale & $0-4,000 \mathrm{~g}$ & $\pm 0.01 \mathrm{~g}$ \\
\hline
\end{tabular}

\section{EXPERIMENTAL DATA ANALYSIS}

study. In our preliminary tests the flue gas temperature entering the MHX was varied but this had very little effect on performance. If this MHX was integrated into a natural gas furnace, then the entering flue gas temperature would be at approximately $150^{\circ} \mathrm{C}$. Limitations of the heat tapes and controllers necessitated all tests to be conducted at a temperature of approximately $148^{\circ} \mathrm{C}$, which is close to the target temperature. Another potential variable was the flow rate of the cooling water around the MHX. However, adjusting the flow rate only yielded a smaller or larger water temperature differential. If the flow rate was too low, then the differential temperature would be too high, which would cause a large temperature gradient from one end of the MHX to the other. If the flow rate was too high, then the differential temperature would be too small and difficult to measure accurately. The pressure on the vacuum side of the MHX where the condensed water is extracted from the MHX could have a minor effect on the performance. However, if the vacuum was too strong (i.e., absolute pressure was too low), then the condensed water could be pulled from the pores, eliminating the benefit of the capillary condensation. The flow through a single tubular membrane element can be used to determine how many membranes are needed for a full-scale MHX system. Doubling the flow rate means the number of membranes needed would be halved. The number of membranes needed is the largest influence on the cost of a full-scale MHX. Two cooling water temperatures $\left(20^{\circ} \mathrm{C}\right.$ and $\left.25^{\circ} \mathrm{C}\right)$ were used in the tests to demonstrate the effect that the temperature of the recirculated conditioned air may have on the performance.

Each test ran for approximately 195 minutes to 224 minutes with an average of 205 minutes. This test length was long enough that a short perturbation of the system to start collecting condensed water would 
have only a minimal effect on the steady-state operation of the system, and it was short enough that two tests could be completed in one day. Removing the flasks for weighing briefly interrupts the vacuum on the water collection port and the flow of flue gas through the MHX. This perturbation is shown in several of the charts in Appendix B. For the first test, the system started under a specific flow rate with a cooling water temperature of $20^{\circ} \mathrm{C}$. The system took $2-3 \mathrm{~h}$ to achieve steady-state conditions. After completion of the first test, the cooling water was adjusted to $25^{\circ} \mathrm{C}$, and the system took less than $30 \mathrm{~min}$ to achieve steady-state conditions again to start the second test. Each test was started by weighing the empty Erlenmeyer flasks, connecting them to the system tubing using rubber stoppers, and placing them into the ice water bath. At the conclusion of the test, the stoppers were removed from the flasks, and the flasks were removed from the ice water bath. The exterior of the flasks were dried, the flasks were weighed again, and then small aliquots were collected for $\mathrm{pH}$ measurements.

The water collection rate, $\mathrm{C} R_{w}(\mathrm{~g} / \mathrm{min})$, was calculated via Eq. (2) using the amount of water collected from the condensate or reject $\left(m_{w}\right)$ and time $(t)$ between the start and the end of the test.

$$
C R_{w}=\frac{m_{w}}{t} .
$$

The rate of latent heat recovered was calculated by multiplying the grams of water collected per minute by the MHX by the heat of vaporization (condensation), $\Delta H_{\text {vap }}$, as shown in Eq. (3).

$$
\text { Heat }_{\text {Latent }}=C R_{w} \times \Delta H_{\text {vap }}
$$

The sensible heat of the flue gas was calculated by multiplying the calculated MHX inlet flue gas flow rate, $F_{\text {flue }}$, by the calculated specific heat capacity of the flue gas, $C_{p}$, and the difference in gas temperature from the inlet of the MHX to the outlet of the MHX ( $\left.T_{\text {in }}-T_{\text {out }}\right)$, as shown in Eq. (4). The $C_{p}$ was calculated at $100^{\circ} \mathrm{C}$ and is the component-weighted average of the individual gas components. Flue gas flow rate entering the MHX was not directly measured because of the high water content, acidity of the flue gas, and high temperature of the flue gas. However, the flow rate of the flue gas exiting the test loop was directly measured. To estimate the flow rate entering the MHX, the water condensed by the MHX and in the reject flask were converted to their equivalent gas volumes and added to the measured flow rate.

$$
\text { Heat }_{\text {Sensible }}=F_{\text {flue }} \times\left(T_{\text {in }}-T_{\text {out }}\right) \times C_{p} .
$$

The water concentration entering the MHX, $m_{w F e e d}$, was calculated using the oxygen concentration measured by the combustion gas analyzer and the stoichiometry for the combustion of methane. Although natural gas was employed for these tests, methane typically represents approximately $95 \%$ of the hydrocarbon content of natural gas, so the stoichiometry calculation would not have changed significantly if a more rigorous and time-consuming calculation were performed. The amount of excess air used for combustion was adjusted until the $\mathrm{O}_{2}$ concentration from the stoichiometry relationship matched the $\mathrm{O}_{2}$ concentration measured by the gas analyzer. The water entering the MHX was accounted for in three places. First, much of the water was condensed by the MHX and collected in the condensate flask $\left(m_{w C}\right)$. Second, a large fraction of the water was collected in the reject flask $\left(m_{w R}\right)$ located in the ice water bath. Third, the water that was not condensed in either flask exited the test system through the flowmeter and out the exhaust duct. The concentration of water that exited the system was calculated using the saturation vapor pressure of water $\left(P_{v a p}\right)$ at the temperature of the flue gas measured above the water in the reject flask. This concentration was multiplied by the flow rate in liters per minute $\left(F_{\text {flue measured }}\right)$ and the molecular weight of water $\left(M W_{\text {water }}\right)$ and divided by the molar volume $\left(V_{\text {mole }}\right)$ in liters per mole, resulting in the total mass of water lost to the exhaust $\left(m_{w T}\right)$. The $m_{w T}$ was calculated using Eq. (5) and was compared with the water entering the $\operatorname{MHX}\left(m_{w F e e d}\right)$ to calculate the percentage of the water that is accounted for in the test (Eq. [6]), which is an indicator of the mass balance in the lab test results. 


$$
\begin{gathered}
m_{w T}=m_{w C}+m_{w R}+\left(F_{\text {flue measured }} \times \frac{P_{\text {vap }}}{101.325} \times M W_{\text {water }}\right) / V_{\text {mole }} \\
\text { Percent water accounted for }=m_{w T} / m_{w F e e d} .
\end{gathered}
$$

Heat recovery ( $\left.\Delta H_{\text {recovered }}\right)$ was also calculated, as shown in Eq. (7). The temperature difference of the cooling water $\left(T_{\text {water out }}-T_{\text {water in }}\right)$ was multiplied by the flow rate of cooling water $\left(F_{\text {water }}\right)$ and the specific heat capacity of water $\left(C_{p \text {,water }}\right)$ :

$$
\Delta H_{\text {recovered }}=F_{\text {water }} \times\left(T_{\text {water out }}-T_{\text {water in }}\right) \times C_{p, \text { water }} .
$$

The $\mathrm{pH}$ of the MHX condensate and the reject condensate samples was measured using a $\mathrm{pH}$ meter. $\mathrm{pH}$ is a logarithmic scale, and a $\mathrm{pH}$ change of 1 equates to a hydrogen ion concentration change of $10 . \mathrm{pH}$ was calculated using Eq. (8).

$$
p H=-\log _{10}\left[H^{+}\right]=\log _{10} \frac{1}{\left[H^{+}\right]},
$$

where $\mathrm{H}^{+}$represents hydrogen ion concentration in solution.

\section{RESULTS AND DISCUSSION}

Four series of tests were conducted. During the first three series, adjustments were made to the test system to collect the relevant data under the desired conditions. The system originally employed a chilled mirror to measure the moisture content of the flue gas, but the high flue gas temperature and its water and acid gas content caused measurement problems owing to condensation and corrosion to the mirror. So the chilled mirror sensor approach was discontinued. Other smaller changes to the test loop were made, including adding stoppers that fit in the flasks better, adding a metering valve that improved cooling water flow, and adjusting piping and thermocouple placement to eliminate air bubbles in cooling water lines and inaccurate temperature measurements. A new humidity sensor was added to measure the moisture content of the combustion air. A new data counter was added for the flue gas flowmeter to reduce the effects of potential electrical interference. The flask collecting condensate from the reject stream was moved closer to the MHX to lower the humidity going through pump. A new larger pump was installed to allow testing at a broader range of flue gas flows. The final modification before the fourth and final series of tests was to move the pump to downstream of the gas flowmeter to eliminate flow measurement inaccuracy caused by air infiltration into the pump. Additional details of the test loop revisions are discussed in Appendix A.

During the analysis of the Series 3 data, the mass and energy balances indicated a potential flue gas pump leak. Tests using rotameter type flowmeters placed at the entrance and exit of the pump showed that the flow out of the pump was significantly higher than the flow into the pump, indicating air infiltration into the pump. A correction factor was determined based on this test and was applied to the Series 3 data. These corrected Series 3 data are compared with the data from Series 4 in Appendix C. This correction was performed to expand the total flow range of the tests. The charts in Appendix $\mathrm{C}$ show that the corrected Series 3 data and Series 4 data follow the same trend. The Series 3 data included do not change the conclusions reached, but they do show how changing the flow further influences the performance of the MHX system.

Table 2 lists the conditions and major measured results of the Series 4 tests. Three tests were performed at varying flue gas flow rates and two different cooling water temperatures $\left(20^{\circ} \mathrm{C}\right.$ and $\left.25^{\circ} \mathrm{C}\right)$. Key pieces of data include the amount of condensed water collected by the MHX and in the reject flask, $\mathrm{pH}$ values of the collected condensate, and the temperature of the flue gas exiting the MHX. The total percentage of 
water accounted for ranged from $\sim 89 \%$ to $\sim 98 \%$ for the six Series 4 tests with an average of $94.4 \%$ $\pm 3.4 \%$. This indicates that the measurements and assumptions in the mass balance calculation for water have a high degree of accuracy. Figure 6 shows the relationship between the latent heat collected as a function of both flue gas flow and cooling water temperature. As the flue gas flow was increased, the amount of water collected by the MHX increased, which directly increases the latent heat recovery. Figure 6 also shows how the latent heat recovery is affected by the cooling water temperature. The $5^{\circ} \mathrm{C}$ increase in the cooling water temperature lowered the latent heat recovered by less than $20 \%$. Figure 7 shows the percentage of latent heat recovered as a function of flue gas flow rate in the single-membrane MHX. This value is essentially the fraction of the total water vapor entering the MHX that is condensed by the MHX. Although Figure 6 shows that the amount of latent heat increases as the flue gas flow increases, the percentage of available latent heat decreases as shown in Figure 7. In these tests, the percentage of latent heat recovered by the prototype MHX ranged from about $25 \%$ to $45 \%$.

Table 2. Conditions and measured results from Series 4 tests

\begin{tabular}{|c|c|c|c|c|c|c|c|c|c|}
\hline \multirow{3}{*}{ Date } & \multirow{3}{*}{$\begin{array}{c}\text { Flue Gas } \\
\text { Flow } \\
\text { (cfm) }\end{array}$} & \multirow{2}{*}{\multicolumn{2}{|c|}{$\begin{array}{c}\text { Cooling Water } \\
\text { Temperature } \\
\left({ }^{\circ} \mathbf{C}\right)\end{array}$}} & \multicolumn{2}{|c|}{ Water Collected } & \multirow{2}{*}{\multicolumn{2}{|c|}{$\mathbf{p H}$}} & \multirow{2}{*}{\multicolumn{2}{|c|}{$\begin{array}{c}\text { Flue Gas } \\
\text { Temperature } \\
\left({ }^{\circ} \mathbf{C}\right)\end{array}$}} \\
\hline & & & & \multirow{2}{*}{$\begin{array}{c}\begin{array}{c}\text { By } \\
\text { MHX }\end{array} \\
(g)\end{array}$} & \multirow{2}{*}{$\frac{\text { Reject }}{(\mathrm{g})}$} & & & & \\
\hline & & $\begin{array}{c}\text { MHX } \\
\text { In }\end{array}$ & $\begin{array}{c}\text { MHX } \\
\text { out }\end{array}$ & & & Condensate & Reject & $\begin{array}{c}\text { MHX } \\
\text { In }\end{array}$ & $\begin{array}{c}\text { MHX } \\
\text { Exit }\end{array}$ \\
\hline $4 / 22 / 21$ & 0.47 & 19.73 & 21.35 & 63.00 & 109.39 & 5.27 & 3.24 & 150.06 & 97.73 \\
\hline $4 / 23 / 21$ & 0.33 & 19.71 & 20.54 & 54.17 & 70.98 & 5.43 & 3.41 & 150.30 & 91.51 \\
\hline $4 / 27 / 21$ & 0.21 & 19.64 & 20.46 & 52.24 & 43.67 & 5.57 & 3.28 & 149.35 & 71.79 \\
\hline $4 / 22 / 21$ & 0.47 & 24.63 & 25.93 & 61.07 & 126.78 & 5.36 & 3.13 & 148.92 & 101.06 \\
\hline $4 / 23 / 21$ & 0.32 & 24.71 & 25.16 & 47.93 & 80.66 & 5.53 & 3.46 & 149.97 & 92.21 \\
\hline $4 / 27 / 21$ & 0.21 & 24.62 & 25.24 & 45.65 & 50.80 & 5.54 & 3.34 & 149.13 & 73.21 \\
\hline
\end{tabular}




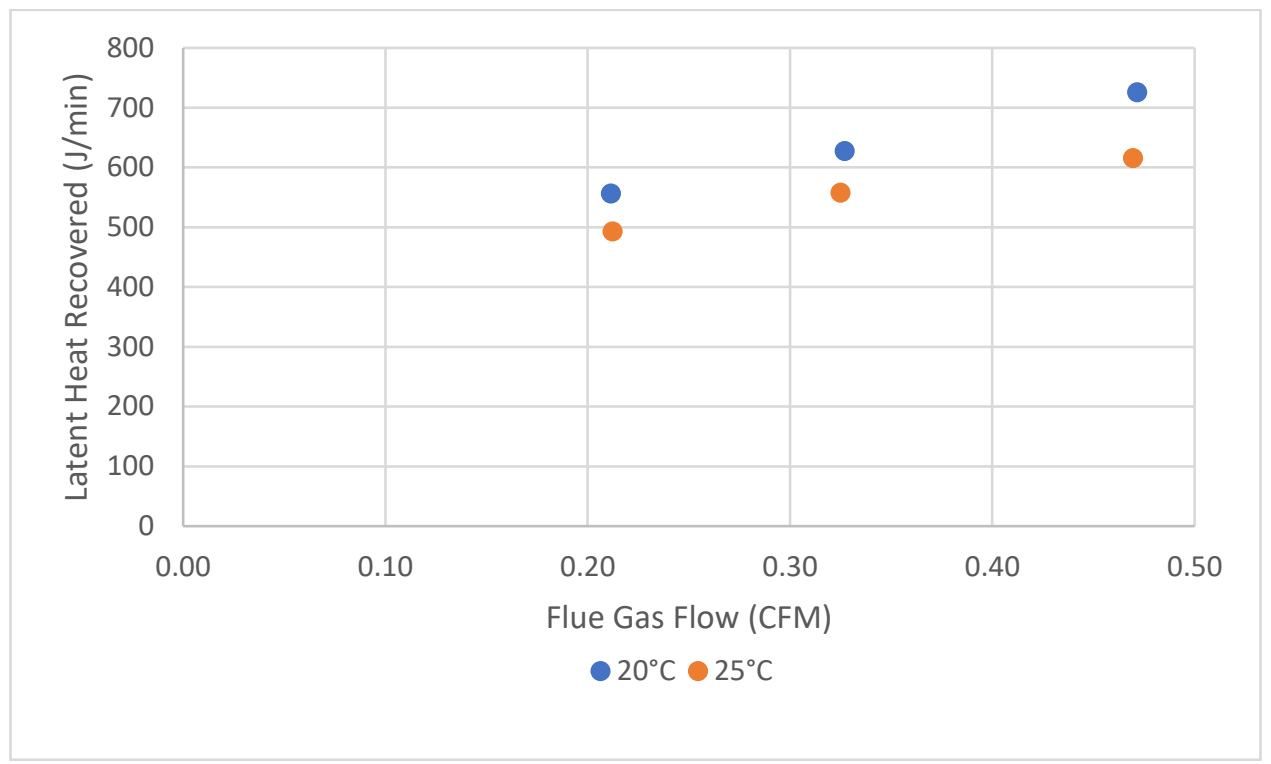

Figure 6. Latent heat recovered by the single-membrane MHX as a function of flue gas flow rate at two different cooling water temperatures.

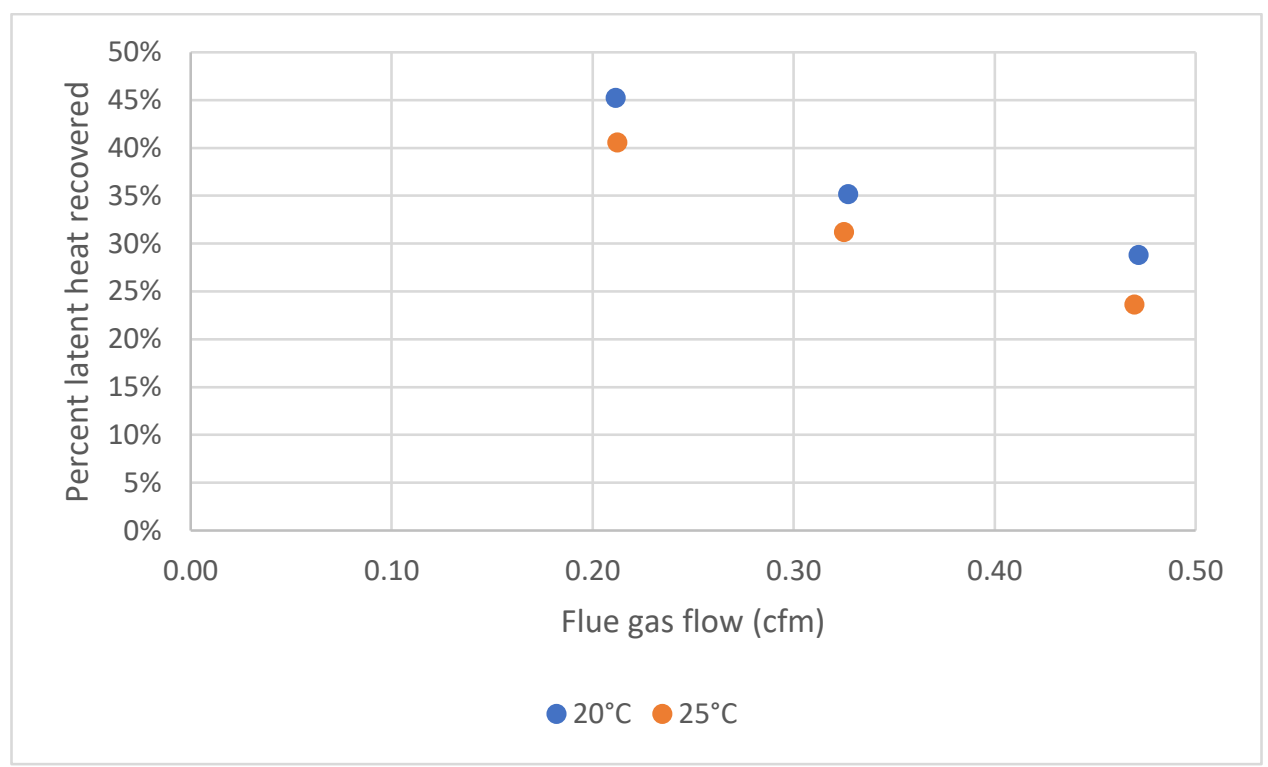

Figure 7. Relationship between the percentage of recovered latent heat and the flue gas flow rate in a single-membrane MHX.

The measured pressure drop down the length of the MHX increased with flue gas flow and ranged from 12.5 $\mathrm{Pa}$ to $44.6 \mathrm{~Pa}$. This represents a pressure drop of less than $0.05 \%$ of the pressure in the MHX which is approximately one atmosphere. These data do not include additional pressure drops from the MHX end fittings added to connect it to the rest of the test loop, but these are expected to be even lower than that through the MHX.

Figure 8 shows the MHX flue gas exit temperature as a function of flue gas flow in a single-membrane MHX. Increasing flue gas flow results in a higher exit temperature. With a $0.47 \mathrm{cfm}$ flue gas flow, the 
exit flue gas temperature reached over $100^{\circ} \mathrm{C}$. Replacing an existing noncondensing furnace could be easier if the temperature and buoyancy of the flue gas from an MHX-based condensing furnace are high enough to allow for use of a Category I venting system per ANSI Standard Z21.47-2006 (ANSI 2006) (e.g., negative pressure, no condensation). In this case, the existing metal vent pipe could be reused to avoid the additional cost of replacing it with a PVC vent or adding a new PVC vent (for cases in which a gas water heater shared the existing vent system) for the furnace.

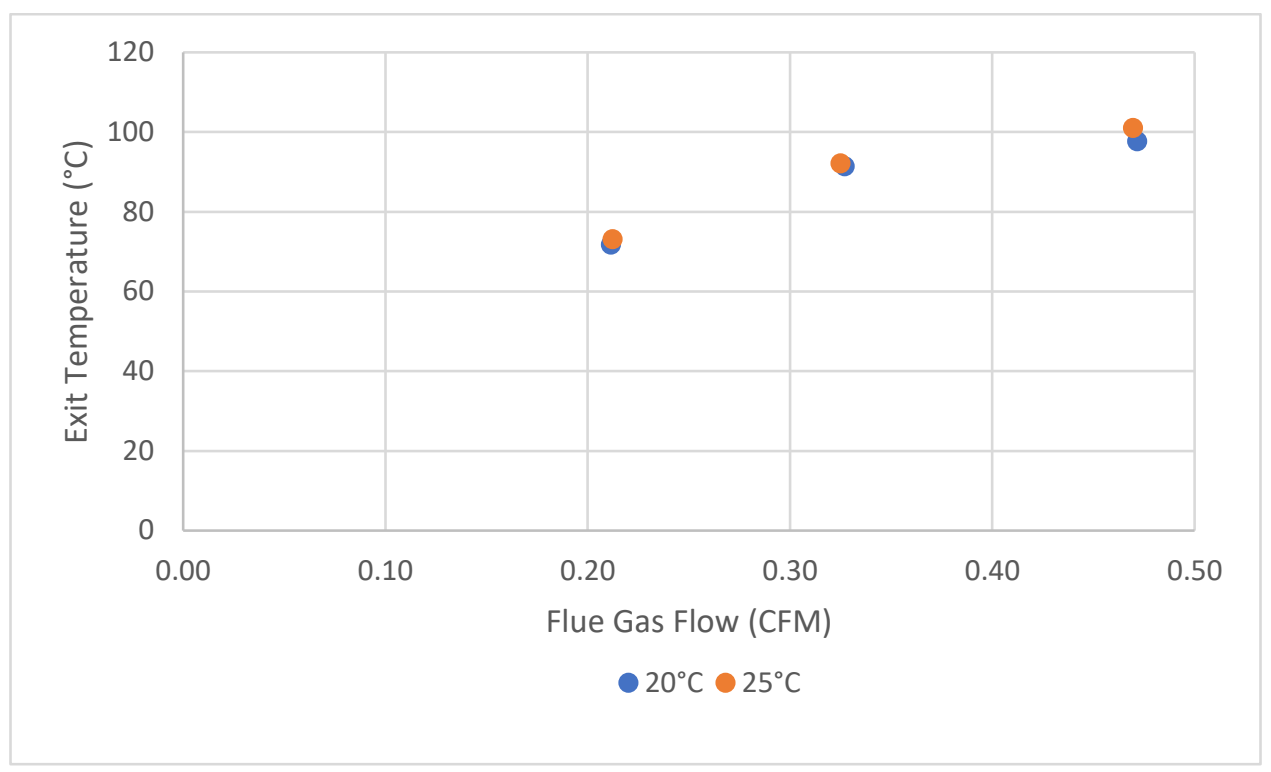

Figure 8. Relationship between MHX exit temperature and the flue gas flow rate in a single MHX.

Figure 9 shows the $\mathrm{pH}$ of the water condensed by the $\mathrm{MHX}$ and the water condensed in the reject flask (typical of water condensed by a conventional condensing furnace). A trend of $\mathrm{pH}$ with flow rate is not apparent. However, the $\mathrm{pH}$ of the water condensed by the MHX is consistently approximately 2.0 to 2.3 $\mathrm{pH}$ units higher than the $\mathrm{pH}$ of the water condensed in the reject flask. This $\mathrm{pH}$ difference indicates that the water condensed by the MHX has less than $1 \%$ of the hydrogen ion concentration, or less than $1 \%$ of the acidity, of the water condensed in the reject flask. This lower acidity may eliminate any need for an acid-neutralizing system for the condensate. The water condensed in the reject flask is comparable to the water that condenses on the surface of a secondary HX because that water is in contact with the flowing flue gas. Both water vapor and the acid gases in the flue gas are condensable, and the acid gases are soluble in water. Capillary condensation occurs in the MHX when the condensable gas molecules are adsorbed on the walls of the pores. As the vapor pressure increases, multilayer adsorption occurs until surface tension effects cause the pores to be filled. In the case of the MHX, water molecules are adsorbed onto the walls and condensed in the pores above a critical concentration. This process is dynamic: the water is continually pulled from the backside of the pores by the vacuum applied to the module. While the condensed water is continually pulled out, new water is condensing in the pores on the side in contact with the flue gas. Therefore, the acid gases do not have time to fully equilibrate with (i.e., dissolve into) the condensed water, yielding lower overall condensate acidity and a higher $\mathrm{pH}$. The water in the reject stream of the test loop is condensed by flowing the flue gas through a flask sitting in an ice water bath. This gas has more contact with the condensed water, yielding higher acidity and a lower $\mathrm{pH}$. 


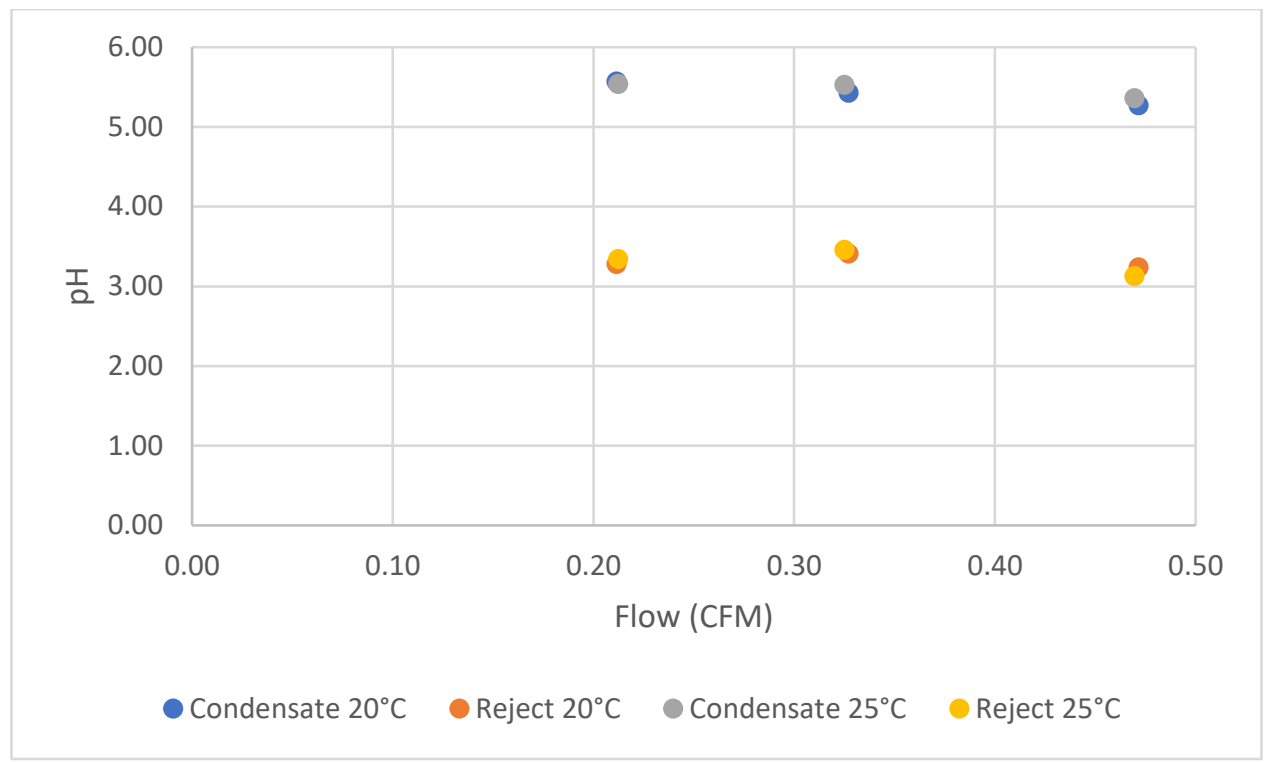

Figure 9. pH values of the MHX condensate and the water condensed in the reject stream under various coolant temperatures and flue gas flow rates in a single MHX.

\section{FULL-SCALE MHX}

The tests for this project were completed using a single 9 in. long prototype MHX with an inner diameter of approximately $0.4 \mathrm{in}$. A full-scale MHX module for an $80,000 \mathrm{Btu} / \mathrm{h}$ gas input furnace would contain a plurality of membranes either as a series of membranes installed into a tube and shell configuration or by employing a monolith with several parallel channels. In this concept, depicted in Figures 10-12, the monolith is constructed of a CGF material. US Patent application 20,200,171,422 (Bischoff et al. 2020) was submitted for a full-scale monolithic membrane design that would be incorporated in a full-scale MHX. The monolithic design would be less expensive to manufacture because fewer seals are required (one for the entire monolith vs. one for each membrane tube), and a heat transfer interface is eliminated. The design incorporating individual membranes requires a transfer of heat (from the condensation process) for each membrane support to the CGF monolith. In the monolith design, the nanoporous membrane layers are applied directly to the CGF, eliminating the transfer of heat to the metallic support and then to the porous graphite. 


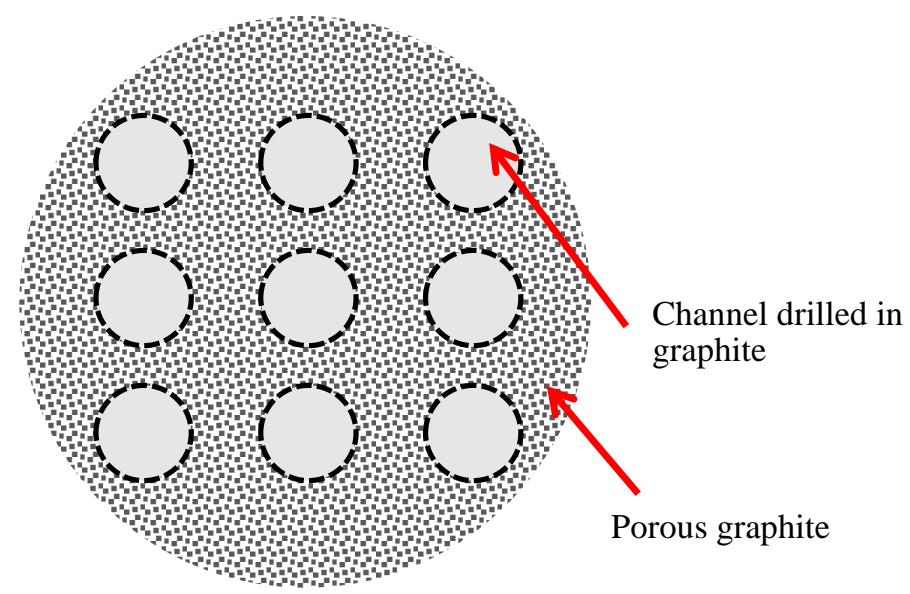

Figure 10. A cross-section of an MHX module with nine channels or membranes in a cylindrical CGF monolith in which the interior surface of each channel is coated with a nanoporous coating.

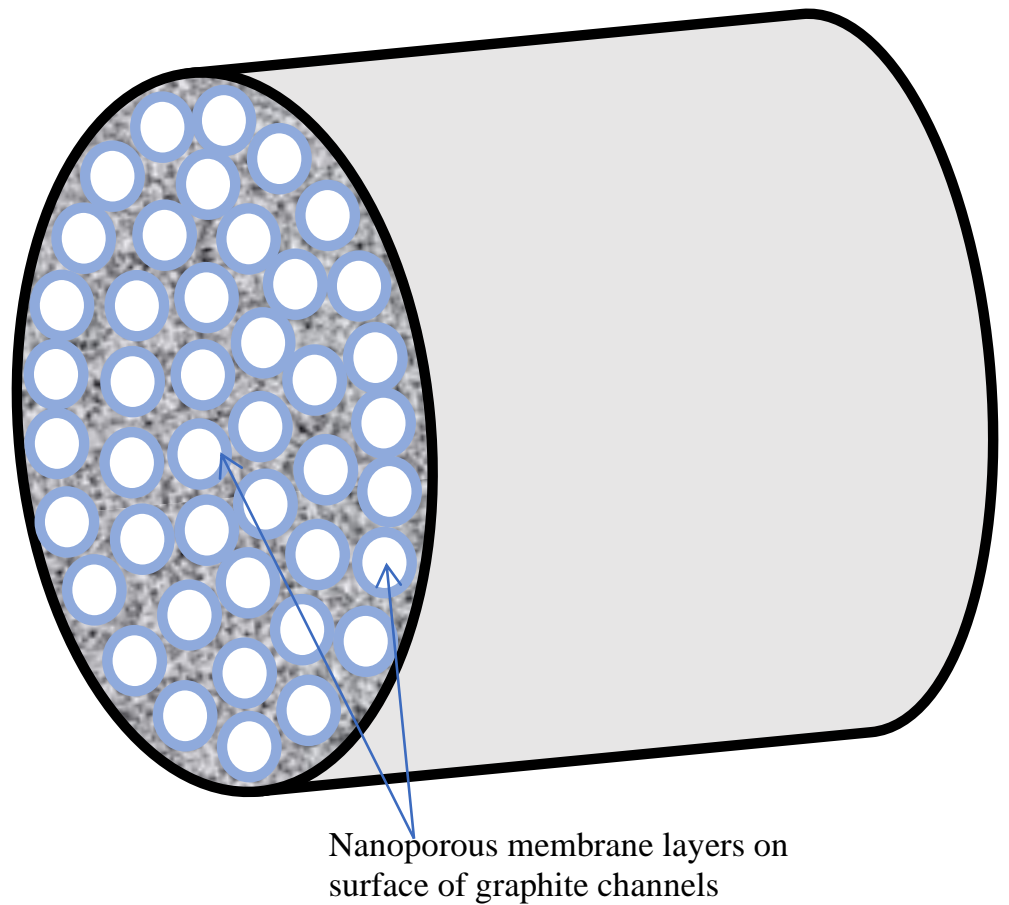

Figure 11. A rendering a cylindrical CGF MHX module with multiple channels. 

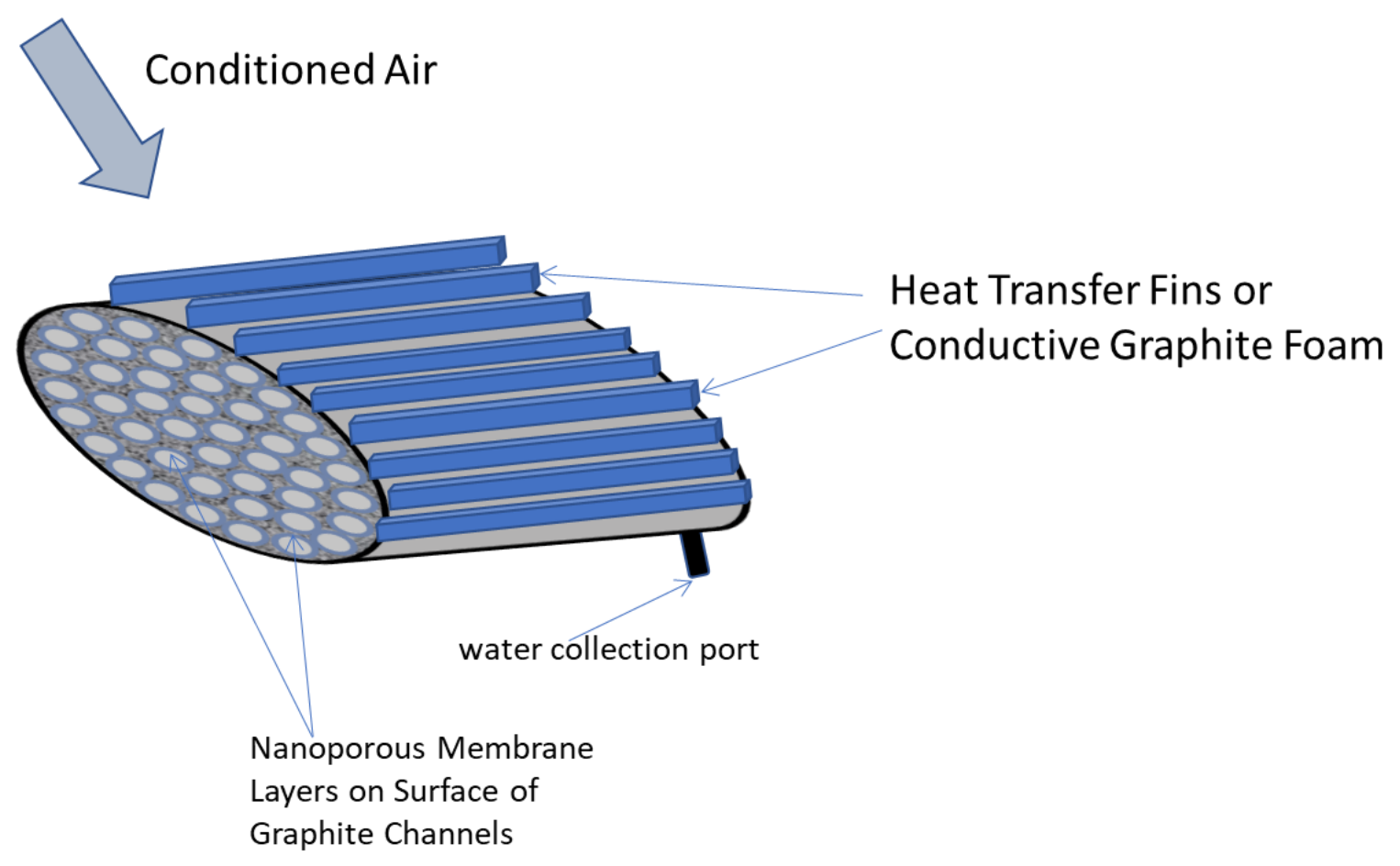

Figure 12. A rendering of an oval-shaped MHX module of CGF with multiple channels.

The high thermal conductivity CGF material was developed at ORNL in the late 1990s and patented (US Patent 6,033,506; Klett 2000). Unlike traditional carbon and graphite foams, the novel ORNL material is a graphite foam with extremely high bulk thermal conductivity equivalent to aluminum, but at one-fifth its weight (Klett 1999). The CGF cell walls are made of oriented graphitic planes that are better aligned than the high-performance carbon fibers currently used in aerospace applications. The individual CGF cells can be fabricated in sizes ranging from $50 \mu \mathrm{m}$ to $1 \mathrm{~mm}$. CGF is also much less expensive than stainless steel; therefore, a much less expensive condensing HX is possible compared with the stainless steel HXs used in current condensing furnaces.

Table 3 summarizes some of the conditions and data for the Series 4 tests and extrapolation to a full-scale MHX, including the size (diameter) required for a 9 in. long MHX monolithic membrane. The monolith size was determined by first determining the number of channels or membranes needed based on the total corrected flue gas flow for a full-size furnace and then dividing by the flow through one membrane as measured in the Series 4 tests. The corrected flow rate was determined by adjusting the full-furnace flow until the furnace achieved a theoretical 100\% efficiency (i.e., all the latent heat and sensible heat were recovered). To determine the monolith diameter, a fill factor of 50\% was applied (i.e., assumed that 50\% of monolith cross-sectional area was occupied by the membrane channels). The calculated diameter of the needed monolith for each test is included in Table 3 (col. 6) and ranged from 4.2 to 6.2 in. for a 9 in. long monolithic membrane. The monoliths contained between 55 and 121 channels.

A furnace efficiency gain due to the MHX was calculated with a two-step approach. First, we calculated the theoretical maximum amount of latent and sensible heat that could be recovered based on flue gas flow rate, temperature, and water content of the flue gas. Second, the total flue gas flow rate $\left(F_{\text {flue_tot }}\right)$ of an $80,000 \mathrm{Btu} / \mathrm{h}$ furnace was calculated to reach a maximum furnace efficiency of $100 \%$. The calculated total flue gas flow rate was then used to scale up the latent and sensible heat recovery rate measured from the prototype MHX tests (recovering heat from a slipstream of the flue gas) to obtain the furnace efficiency gain that can be achieved by a full-size MHX (recovering heat from all the flue gas), as 
expressed with Eq. 9. This gain was added to the base efficiency of $82 \%$ to yield the new furnace efficiency (Eq. 10) and recorded in column 5 of Table 3 below.

Furnace Efficiency Gain $=\frac{\frac{F_{\text {flue_Tot_Adj }}}{F_{\text {flue }}} \times\left(\text { Heat }_{\text {Latent }}+\text { Heat }_{\text {Sensible }}\right)}{\text { Heat input of furnance }}$

New Furnace Efficiency = Base Efficiency (82\%) + Furnace Efficiency Gain

Figure 11 shows a simple cross-section of a module with nine channels. Each channel has a nanoporous coating applied to the interior surface of channels machined into the CGF substrate material. Figures 11 and 12 show conceptual drawings of a cylindrical monolithic membrane and an oval-shaped air-cooled module concept with fins in the exterior surface for increasing heat transfer between the MHX and the air to be conditioned. The module can be made in almost any shape to accommodate the available space in a furnace. A 9 in. long by 6 in. diameter module plus associated hardware, flanges, and so on could fit in a standard home furnace of the dimensions shown in Figure 13.

Table 3. Summary of Series 4 conditions and extrapolation to a full-sized 80,000 Btu/h gas input furnace

\begin{tabular}{|c|c|c|c|c|c|c|}
\hline Date & $\begin{array}{c}\text { Flue gas } \\
\mathbf{f l o w} \\
(\mathbf{c f m})\end{array}$ & $\begin{array}{c}\text { Cooling } \\
\text { temperature } \\
\left({ }^{\circ} \mathbf{C}\right)\end{array}$ & $\begin{array}{c}\text { Corrected full- } \\
\text { furnace flow } \\
(\mathbf{c f m})\end{array}$ & $\begin{array}{c}\text { Corrected } \\
\text { adjusted } \\
\text { efficiency } \\
(\mathbf{\%})\end{array}$ & $\begin{array}{c}\text { Diameter } \\
\text { of 9 in. long } \\
\text { MHX } \\
(\mathbf{i n} .)\end{array}$ & $\begin{array}{c}\text { MHX exit } \\
\text { temperature } \\
\left({ }^{\circ} \mathbf{C}\right)\end{array}$ \\
\hline $4 / 22 / 21$ & 0.47 & 20.54 & 25.9 & 88.9 & 4.20 & 97.7 \\
\hline $4 / 23 / 21$ & 0.33 & 20.06 & 25.6 & 90.0 & 5.03 & 91.5 \\
\hline $4 / 27 / 21$ & 0.21 & 20.06 & 25.2 & 92.5 & 6.20 & 71.8 \\
\hline $4 / 22 / 21$ & 0.47 & 25.33 & 25.9 & 88.1 & 4.23 & 101.1 \\
\hline $4 / 23 / 21$ & 0.32 & 24.98 & 25.7 & 89.5 & 5.06 & 92.2 \\
\hline $4 / 27 / 21$ & 0.21 & 24.96 & 25.5 & 91.8 & 6.22 & 73.2 \\
\hline
\end{tabular}




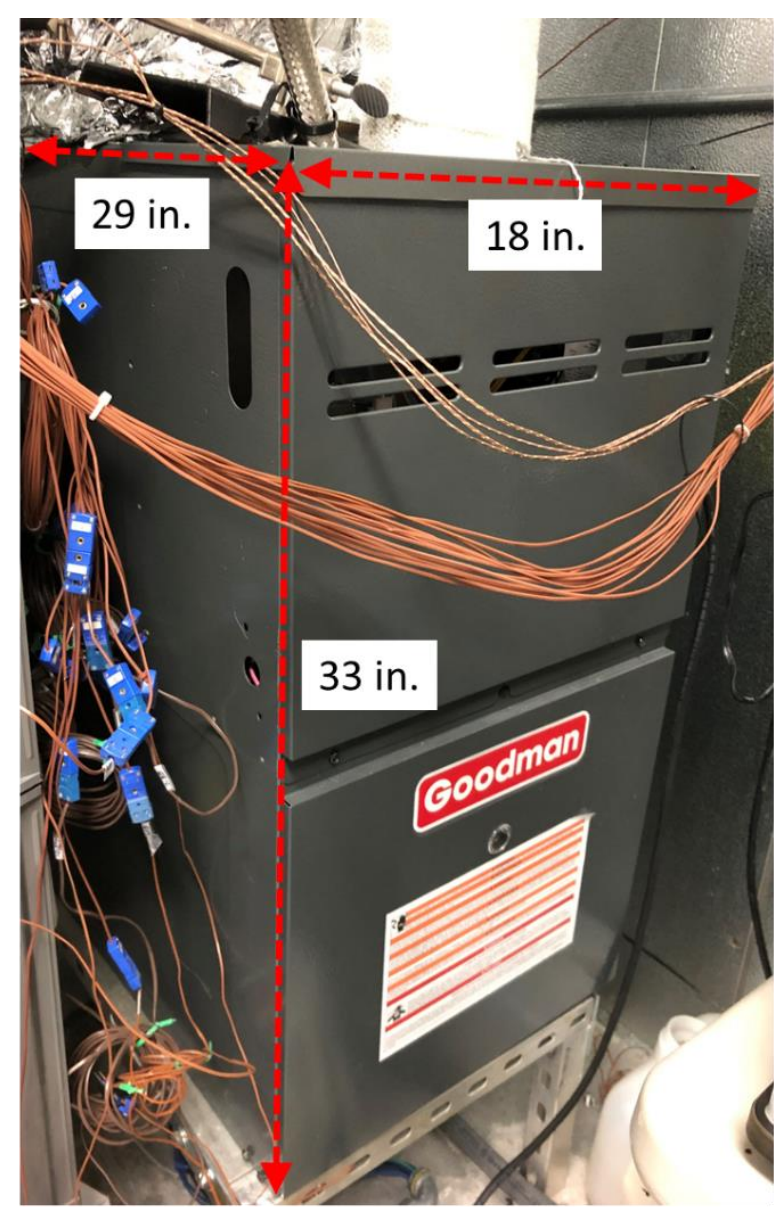

Figure 13. Furnace dimensions.

Figures 14-16 show how the efficiency varies with flow through a single-membrane MHX, full-scale monolith diameter, and MHX exit temperature. Achieving a high MHX exit temperature requires higher flow through the MHX, which results in lower efficiency and a smaller full-scale MHX. Therefore, the need for higher efficiency must be balanced with higher MHX exit temperature and MHX size. 


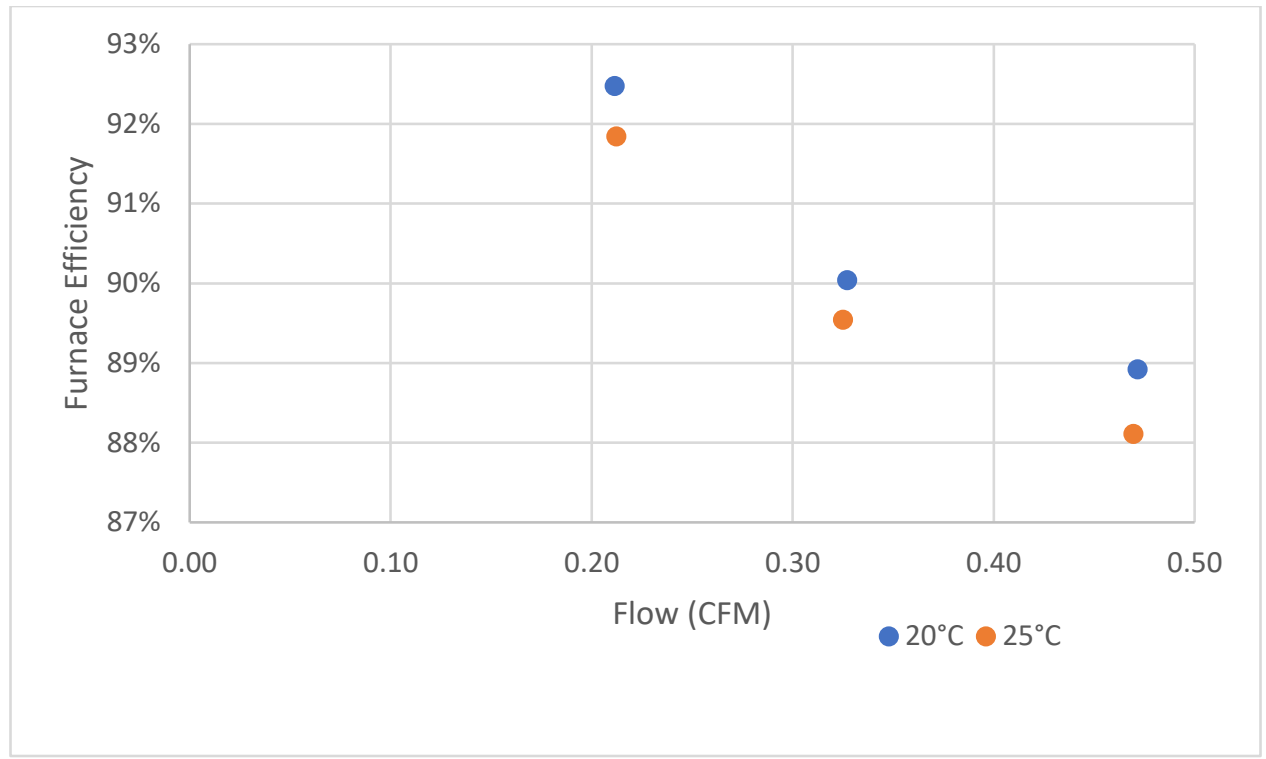

Figure 14. Furnace efficiency as a function of flue gas flow.

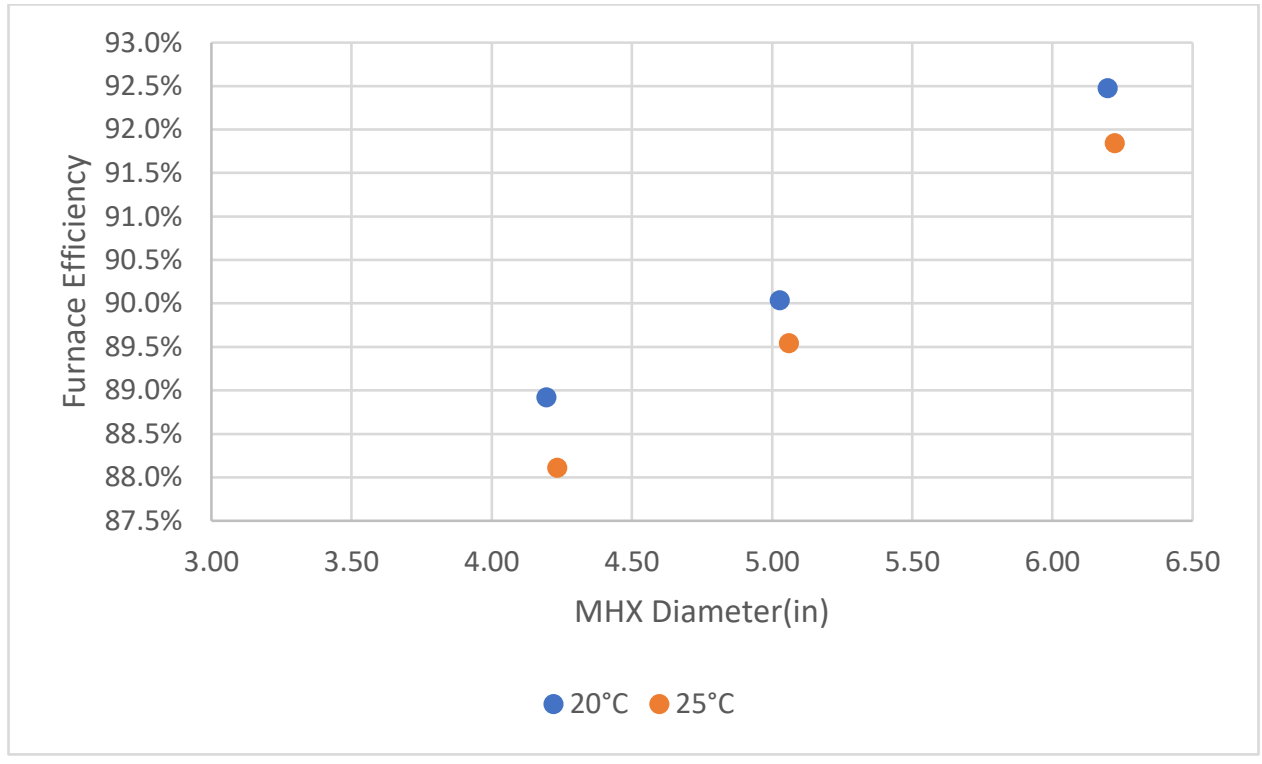

Figure 15. Furnace efficiency as a function of MHX membrane monolith diameter. 


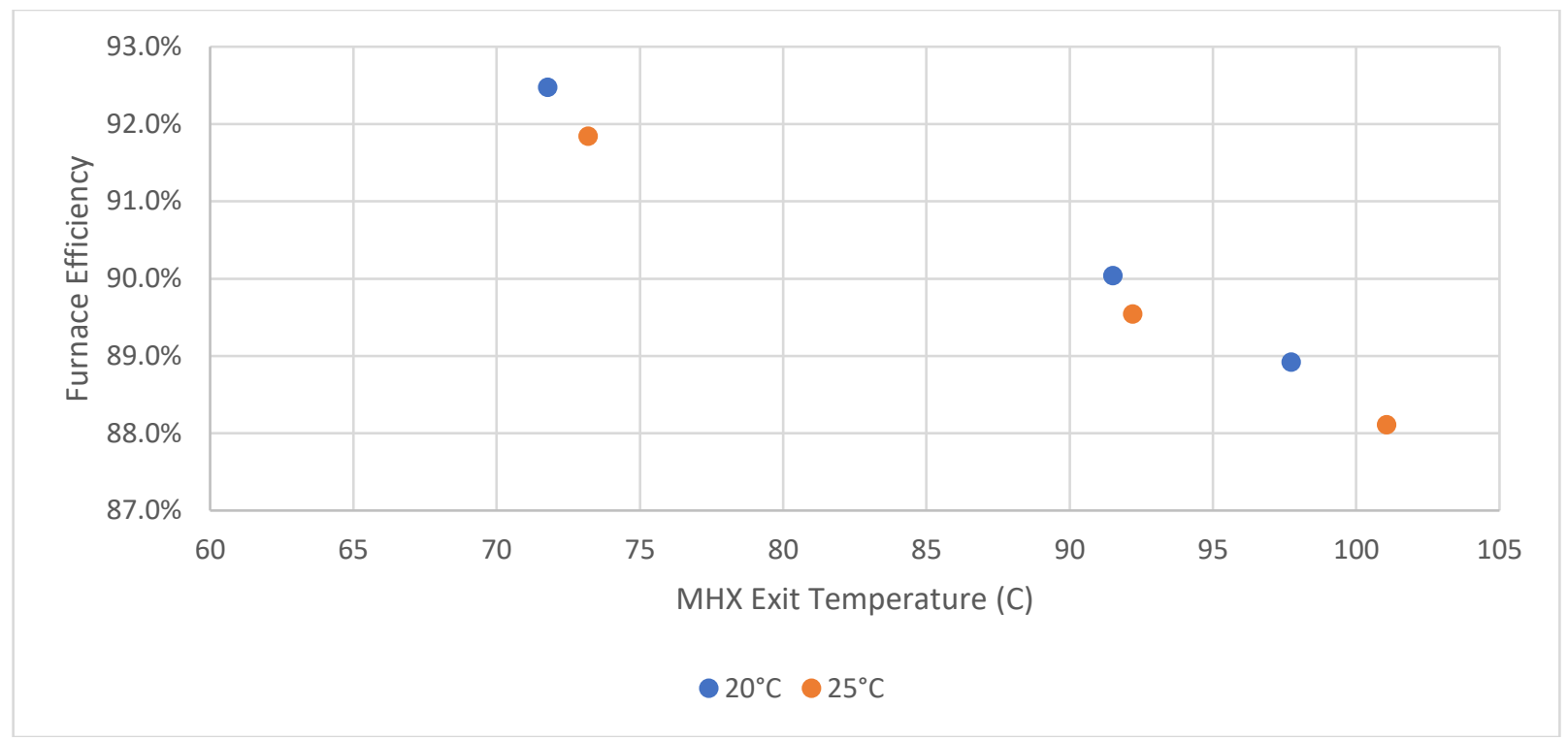

Figure 16. Furnace efficiency as a function of MHX exit temperature.

Advanced Nanomembrane Coating on CGF substrate-Preliminary Development. Several initial trials to apply nano alumina to a CGF surface were completed by employing sol-gel processing. Very limited literature discussion explains how to coat graphitic materials using sol-gel processing. Therefore, modifications to the standard process were required to improve the coating process. The sol-gel process (Brinker and Scherer 1990) is a two-step process in which a sol is prepared and then gelated. A sol is a stable suspension of fine particles or fine polymeric chains in either an aqueous or organic solvent. In this work, an alumina sol was prepared for the coating process. Figure 17(a) shows phase separation in the initial formulation of the alumina sol, indicating the large alumina agglomerate particulates have precipitated out of the aqueous suspension. Figure 17(b) shows that the stability has improved after peptization with nitric acid. The peptization process involves adding the acid and refluxing until the sol stabilizes. During the process, the surface of the individual alumina particles becomes positively charged by the acid, and the charged particles repel each other, forming smaller and less strongly agglomerated particulates. These smaller positively charged agglomerates do not precipitate out of suspension. Also, because the bonds are weaker, the agglomerates can rearrange themselves during the coating process to form a stable, tightly packed coating as the water is removed during gelation in the sol-gel process. 

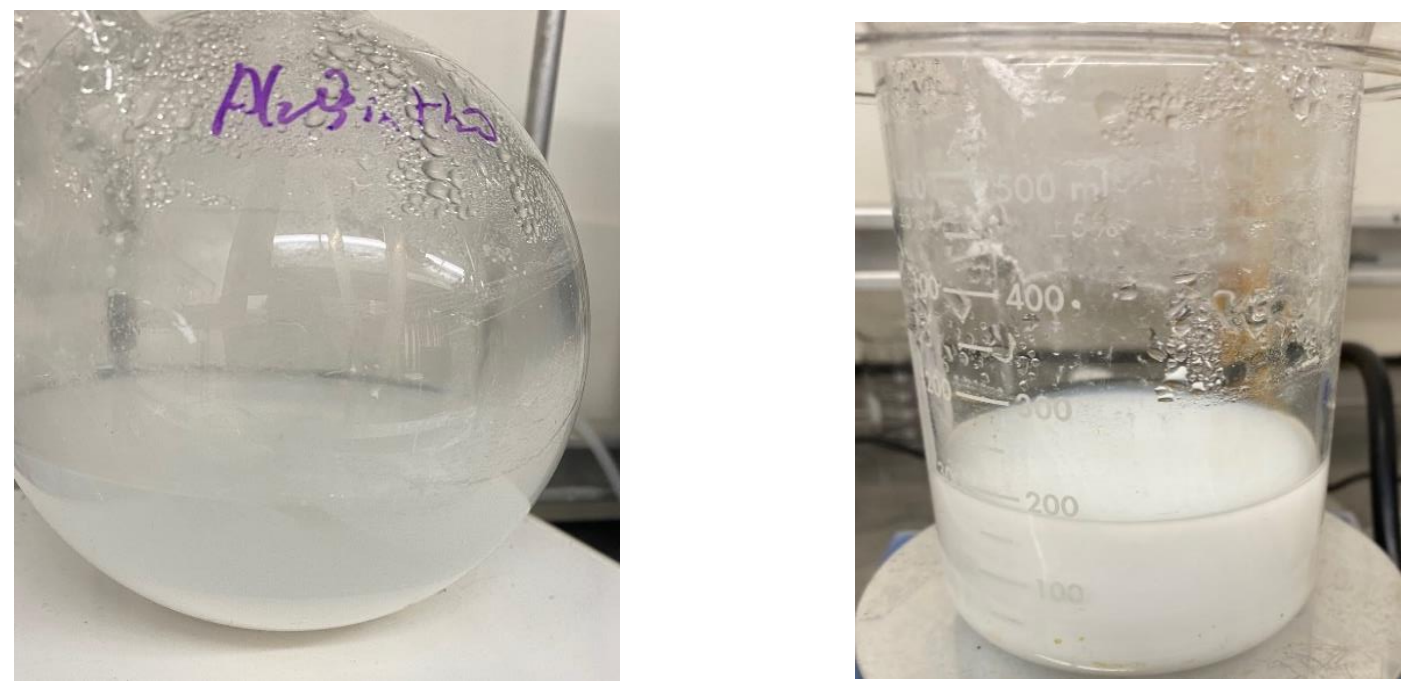

Figure 17. Two alumina sols that will be used to coat the CGF. Initial formation of the alumina sol (left) and stabilized alumina sol after peptization (right).

For the coating process, an acid treatment was first performed on the CGF to make it more hydrophilic and improve the adhesion of the sol particles, as shown in Figure 18. The surfaces of the initial CGF samples were relatively rough (surface pore sizes from 100 to $200 \mu \mathrm{m}$ ), and achieving a uniform thin coating proved to be very difficult with the alumina nanopore materials. A thin, nonviscous sol is pulled too easily into the large pores and does not form a fully bridged coating on the pores.

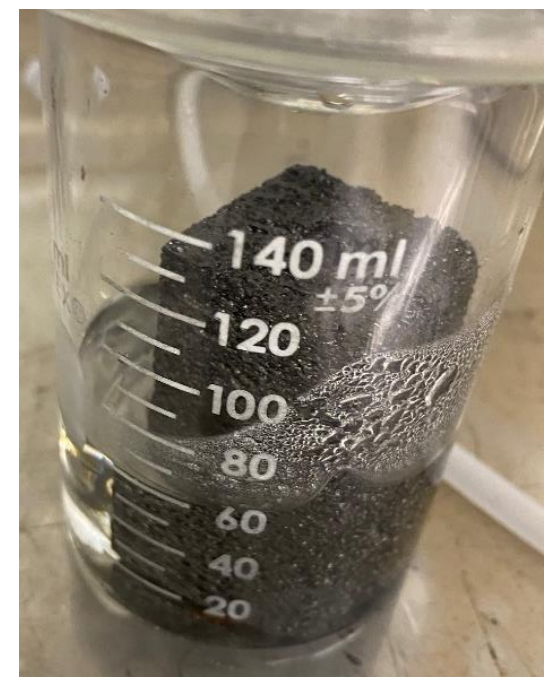

Figure 18. Acid treatment on CGF to increase hydrophilicity of the graphite surface.

To improve the coating process, a two-pronged approach is planned. Crosslinkers will be added in the alumina sol to form a more viscous and suitable coating solution on the tough surface of CGF in the future study. Also, a new series of CFG substrate prototypes with smaller pore size was produced to improve the adhesivity and homogeneity of the nano alumina coating. The more viscous sol will not penetrate as easily into the new, smaller CGF pores and should form a more uniform coating. 


\section{MHX VALUE PROPOSITION AND INSTALLED COST REDUCTION POTENTIAL}

Tables 4-6 illustrate possible cost advantages for MHX-equipped furnaces over conventional condensing furnace technology. These tables are excerpts from the 2015 DOE technical support document from the last furnace rulemaking (DOE 2015). As noted, the total installed cost premium in 2013 for a $90 \%-98 \%$ AFUE condensing furnace over an $80 \%$ AFUE noncondensing furnace was approximately $\$ 480-\$ 820$ (2013 dollars) for a new installation (Table 5). In replacement cases (Table 6), flue venting and condensate removal costs add an additional approximately $\$ 365$ to a condensing furnace installation cost. The reduced condensate acid level achievable by the MHX technology could greatly reduce or potentially eliminate the extra condensate removal cost. If an MHX-based furnace technology could qualify for an ANSI Category I rating (per ANSI 2021), then the additional flue venting costs could also be reduced or eliminated. For an additional 19\% of replacement cases in which an existing gas water heater shared a vent with the replaced furnace (i.e., orphaned water heater problem), another approximately $\$ 675$ is required to provide venting for the water heater. If an MHX-based furnace can achieve the Category I rating, then the replacement venting cost for the water heater could also be eliminated.

Table 4. Average 2012 consumer purchase price for residential furnaces, 2013 dollars (from DOE 2015)

\begin{tabular}{|c|c|c|c|}
\hline \multirow{4}{*}{ Product Class } & AFUE & $\begin{array}{c}\text { Average Consumer } \\
\text { Price } \\
(2013 \$)\end{array}$ & $\begin{array}{c}\text { Incremental } \\
\text { Cost } \\
(2013 \$)\end{array}$ \\
\hline \multirow{4}{*}{$\begin{array}{c}\text { Non-Weatherized Gas } \\
\text { Furnace }\end{array}$} & $\mathbf{8 0 \%}$ & $\mathbf{\$ 1 , 1 6 3 . 4 2}$ & - \\
\cline { 2 - 4 } & $\mathbf{9 0 \%}$ & $\mathbf{1 1 , 3 2 6 . 5 8}$ & $\mathbf{\$ 1 6 3 . 1 6}$ \\
\cline { 2 - 4 } & $\mathbf{9 2 \%}$ & $\mathbf{\$ 1 , 3 4 2 . 6 1}$ & $\mathbf{\$ 1 7 9 . 1 9}$ \\
\cline { 2 - 4 } & $\mathbf{9 5 \%}$ & $\mathbf{\$ 1 , 4 7 6 . 8 7}$ & $\mathbf{\$ 3 1 3 . 4 5}$ \\
\hline \multirow{3}{*}{$\begin{array}{c}\text { Mobile Home Gas } \\
\text { Furnace }\end{array}$} & $\mathbf{9 8 \%}$ & $\mathbf{\$ 1 , 6 6 9 . 1 8}$ & $\mathbf{\$ 5 0 5 . 7 6}$ \\
\cline { 2 - 4 } & $\mathbf{8 0 \%}$ & $\mathbf{\$ 8 1 6 . 3 2}$ & $\mathbf{\$ 1 5 8 . 3 7}$ \\
\cline { 2 - 4 } & $\mathbf{9 2 \%}$ & $\mathbf{\$ 9 7 4 . 6 8}$ & $\mathbf{\$ 3 0 1 . 6 2}$ \\
\cline { 2 - 4 } & $\mathbf{9 5 \%}$ & $\mathbf{\$ 1 , 1 1 7 . 9 3}$ & $\mathbf{\$ 4 1 6 . 6 4}$ \\
\hline
\end{tabular}

Table 5. Average total installed cost for residential furnaces, 2013 dollars (from DOE 2015)

\begin{tabular}{|c|c|c|c|}
\hline \multirow{4}{*}{ Product Class } & AFUE & $\begin{array}{c}\text { Average Total Installed } \\
\text { Cost } \\
(\mathbf{2 0 1 3} \$)\end{array}$ & $\begin{array}{c}\text { Incremental } \\
\text { Cost } \\
(2013 \$)\end{array}$ \\
\hline \multirow{4}{*}{$\begin{array}{c}\text { Non-Weatherized Gas } \\
\text { Furnace }\end{array}$} & $\mathbf{8 0 \%}$ & $\mathbf{\$ 2 , 2 1 8 . 3 5}$ & - \\
\cline { 2 - 4 } & $\mathbf{9 0 \%}$ & $\mathbf{\$ 2 , 6 9 6 . 2 8}$ & $\$ 477.93$ \\
\cline { 2 - 4 } & $\mathbf{9 2 \%}$ & $\mathbf{\$ 2 , 7 1 2 . 3 1}$ & $\$ 493.96$ \\
\cline { 2 - 4 } & $\mathbf{9 5 \%}$ & $\mathbf{\$ 2 , 8 4 6 . 5 7}$ & $\mathbf{\$ 6 2 8 . 2 2}$ \\
\hline \multirow{3}{*}{$\begin{array}{c}\text { Mobile Home Gas } \\
\text { Furnace }\end{array}$} & $\mathbf{9 8 \%}$ & $\mathbf{\$ 3 , 0 3 8 . 8 8}$ & $\mathbf{\$ 8 2 0 . 5 3}$ \\
\cline { 2 - 4 } & $\mathbf{8 0 \%}$ & $\mathbf{\$ 1 , 5 5 1 . 1 5}$ & $\mathbf{\$ 1 6 9 . 4 4}$ \\
\cline { 2 - 4 } & $\mathbf{9 2 \%}$ & $\mathbf{\$ 1 , 7 2 0 . 5 9}$ & $\mathbf{\$ 3 1 2 . 6 9}$ \\
\cline { 2 - 4 } & $\mathbf{9 5 \%}$ & $\mathbf{\$ 1 , 9 6 3 . 8 4}$ & $\mathbf{\$ 4 2 7 . 7 2}$ \\
\hline
\end{tabular}


Table 6. Additional installation costs for nonweatherized gas furnaces in replacement applications, 2013 dollars (from DOE 2015)

\begin{tabular}{|c|c|c|}
\hline Installation Cost Adder & $\begin{array}{l}\text { Replacement Installations } \\
\text { Impacted }\end{array}$ & $\begin{array}{c}\text { Average Cost } \\
(2013 \$)\end{array}$ \\
\hline \multicolumn{3}{|c|}{ Non-Condensing Furnaces } \\
\hline Updating Flue Vent & $2 \%$ & $\$ 555.95$ \\
\hline \multicolumn{3}{|c|}{ Condensing Furnaces } \\
\hline New Flue Venting (PVC) & $100 \%$ & $\$ 296.12$ \\
\hline Combustion Air Venting (PVC) & $59 \%$ & $\$ 295.36$ \\
\hline Concealing Vent Pipes & $9 \%$ & $\$ 360.25$ \\
\hline Orphaned Water Heater & $19 \%$ & $\$ 672.09$ \\
\hline Condensate Removal & $100 \%$ & $\$ 70.06$ \\
\hline
\end{tabular}

Another issue with Category I venting is the potential for condensation to occur in the flue pipes if a standard noncondensing central furnace with AFUE greater than approximately $82 \%-83 \%$ is used. This issue is reflected in the category test described in ANSI 2021. However, an MHX-equipped condensing furnace would remove some of the moisture from the flue gas stream, potentially lowering the dew point temperature enough to avoid any condensation in the vent pipes.

The potential installation cost reductions achievable with an MHX-based condensing furnace must be weighed against any increase in cost compared with conventional condensing furnaces. MHX technology development should continue to determine the potential installation cost savings of MHX condensing furnaces more precisely vs. conventional condensing furnaces.

The highest flue gas exit temperature was approximately $101^{\circ} \mathrm{C}$, measured during a Series 4 test, with an estimated furnace efficiency of approximately $88 \%$ (Tables 3 and 4). For that test, the percentage of $\mathrm{CO}_{2}$ in the flue gas, measured by the combustion gas analyzer, was $5.3 \%$ (or $5.9 \%$ on a dry basis). According to Figure 7 in ANSI Standard Z41.47:21 (ANSI 2021), meeting the requirement for a Category I rating would require that the flue gas $\mathrm{CO}_{2}$ be less than about $4.4 \%$ with the $101^{\circ} \mathrm{C}$ flue gas temperature, or the flue gas temperature would have to be at least $115^{\circ} \mathrm{C}$. Therefore, a furnace using the MHX would have to operate with either more excess air or a higher flue gas flow rate. A higher flue gas flow rate in each channel of a full-sized MHX would result in a lower fraction of latent heat recovery, leading to correspondingly lower potential efficiency gains than those estimated from the prototype MHX tests. Higher flue gas flow in each channel would reduce the total number of channels required for a full size MHX, leading to a smaller, less costly MHX component. A trade-off between efficiency gains and associated costs is needed for retrofitting a noncondensing furnace with the MHX. Further follow-up work is recommended to determine whether an MHX-based furnace could avoid any potential condensation issues with Category I venting and how avoiding potential condensation issues would affect the overall efficiency potential of the MHX-based furnace concept.

\section{CONCLUSIONS}

A bench-scale prototype single-channel tubular MHX was developed and tested using a conventional noncondensing furnace. Test results proved that the MHX can recover latent heat of water vapor without generating acidic condensation.

The condensate rate and reject rate increased with an increasing flue gas flow rate in the MHX, whereas the condensate rate decreased with an increasing coolant temperature. The fraction of latent heat recovery 
decreased with an increasing flue gas flow rate and coolant temperature. The fraction of latent heat recovery varied from $25 \%$ to $45 \%$. Both the sensible heat and latent heat of the water vapor in the flue gas were recovered. The $\mathrm{pH}$ value of the membrane condensate varied from about 5.0 to 5.6 compared with about 3.0 to 3.3 for condensate from a conventional condensing furnace (i.e., an acidity reduction of about 97\%-99\%). Reduced acidity of the condensate means that lower-cost materials can be used for components in contact with the condensate.

The MHX could enable wider market penetration of highly energy-efficient condensing furnaces in several ways: (1) by reducing costs for addressing acid condensation, (2) by enabling the use of existing flue venting systems in replacement situations by operating at higher flue gas exit temperatures, and (3) by employing a condensing HX that has a potentially lower initial cost than that of the condensing HXs used in conventional condensing furnaces. The results of this experimental study provide guidance for further work to develop and demonstrate the feasibility of a scaled-up, optimal prototype furnace design using the MHX technology.

\section{FUTURE WORK}

This study was based on tests and analyses of a prototype MHX consisting of a single membrane element installed in a membrane holder and using cold water as the heat transfer medium for recovering the latent and sensible heat. Based on this reported work the following further development activities are recommended.

Further follow-up work is recommended to determine whether an MHX-based furnace could avoid any potential condensation issues with Category I venting and how avoiding condensation issues would affect the overall efficiency potential of the MHX-based furnace concept.

The MHX technology development should be continued to determine the potential installation cost savings of the MHX condensing furnace option more precisely vs. conventional condensing furnaces.

Development of a potentially lower-cost membrane approach based on the use of CGF as the membrane substrate should be continued.

The prototype MHX investigated and tested in this study was based on a single-membrane tube using a slipstream sample of the flue gas from a noncondensing furnace and a chilled water stream as the heat rejection medium. However, a full-scale residential gas furnace would need to process the full flue gas exhaust stream and employ air as the heat transfer medium. Initial work on a MHX design concept for the full-scale furnace application was initiated, and US Patent application 20,200,171,422 (Bischoff et al. 2020) was submitted. Future work is recommended to further develop and verify performance of a prototype full-scale (80,000 Btu/h gas input) furnace based on the full-scale MHX concept. The full-scale MHX would be made from a single monolithic piece of CGF equipped with a series of parallel channels for the flue gas flow. The inside surface of the channels would be coated with the nanoporous material to provide the capillary condensation capability. This membrane design approach will cost much less than using a series of individual membranes together and would eliminate one heat transfer surface. In the prototype MHX that was tested, the heat was transferred from the alumina membrane layer to the stainless steel tube substrate, then from the porous stainless steel substrate tube to the porous graphite, and then from the porous graphite to the MHX shell. With the monolithic membrane, each alumina layer will be applied directly to the conductive graphite, eliminating the heat transfer resistance of the stainless steel layer.

In addition to the space-heating furnace application, the membrane technology could also be applied to other end uses. For instance, it can be used to recover latent heat from any process that burns hydrocarbon 
fuel, including natural gas, propane, gasoline, diesel fuel, biofuels, and heating oil. In fact, biomassderived oils contain a significant amount of water, and additional water is produced when they are burned. The MHX can recover the latent heat from many other industrial processes involving drying. Some examples of potential applications include lime kilns, recovery boilers, hog fuel boilers, calciners, paper processing (drying raw paper), food drying, biomass processing, and appliances such as clothes dryers and dishwashers.

Discussions with prospective industrial partners have been ongoing to partner in cooperative research and development agreements or other arrangements to advance the technology further toward eventual market introduction.

\section{REFERENCES}

ANSI (American National Standards Institute). 2021. ANSI Standard Z21.47:21 Gas-fired central furnaces, 8th edition. American National Standards Institute.

Bischoff, B. L., J. W. Klett, and M. M. DeBusk. 2020. "Lightweight Inorganic Membrane Module.” US Patent Application 20,200,171,422 filed December 3, 2019, and issued June 4, 2020.

Brinker, C. J., and G. W. Scherer. 1990. Sol-Gel Science: The Physics and Chemistry of Sol-Gel Processing, 1st Edition. Academic Press. Boston.

DOE (US Department of Energy). 2015. Technical Support Document: Energy Efficiency Program for Consumer Products and Commercial and Industrial Equipment: Residential Furnaces. February 10, 2015.

EIA (US Energy Information Administration). 2017. Annual Energy Outlook 2017. Washington, DC. https://www.eia.gov/pressroom/presentations/sieminski_01052017.pdf; accessed June 2019.

Energy Star. 2020. Unit Shipment and Market Penetration Report Calendar Year 2020 Summary. https://www.energystar.gov/sites/default/files/asset/document/2019\%20USD\%20Summary\%20Repor t.pdf; accessed October 2021.

Gregg, S. J. and K. S. W. Sing. 1982. Adsorption, Surface Area and Porosity. Academic Press, London.

Hu, M. Z., B. L. Bischoff, M. E. Morales-Rodriguez, K. A. Gray, and B. H. Davison. 2019. "Superhydrophobic or Hydrophilic Porous Metallic/Ceramic Tubular Membranes for Continuous Separations of Biodiesel-Water W/O and O/W Emulsions." Industrial \& Engineering Chemistry Research, 58: 1114-1122.

Hu, M. Z., C. Engtrakul, B. L. Bischoff, G. G. Jang, T. J. Theiss, and M. F. Davis. 2017. "Superhydrophobic and super hydrophilic surface-enhanced separation performance of porous inorganic membranes for biomass-to-biofuel conversion applications." Separation Science and Technology, 52 (3): 528-543. DOI:10.1080/01496395.2016.1260144.

Judkins, R. R., B. L. Bischoff, M. M. Debusk, and C. Narula. 2013. "Reclamation of potable water from mixed gas streams." US Patent 8,511,072 filed March 24, 2011, and issued August 20, 2013.

Klett, J., 1999. "High Thermal Conductivity, Mesophase Pitch-Derived Graphitic Foams.” Journal of Composites in Manufacturing, 15(4): 1-7.

Klett, J. 2000. "Process for Making Carbon Foam.” US Patent 6,033,506

filed September 2, 1997, and issued March 7, 2000. 
Lutz, J., A. Lekov, P. Chan, C. D. Whitehead, S. Meyers, and J. McMahon. 2006. "Life-cycle cost analysis of energy efficiency design options for residential furnaces and boilers." Energy 31: 311329. 


\section{APPENDIX A. \\ Project Test Loop Development Iterations}

This appendix describes the evolution history of the membrane heat exchanger (MHX) test loop apparatus.

Test series 1: 6/24/2020-7/27/2020 

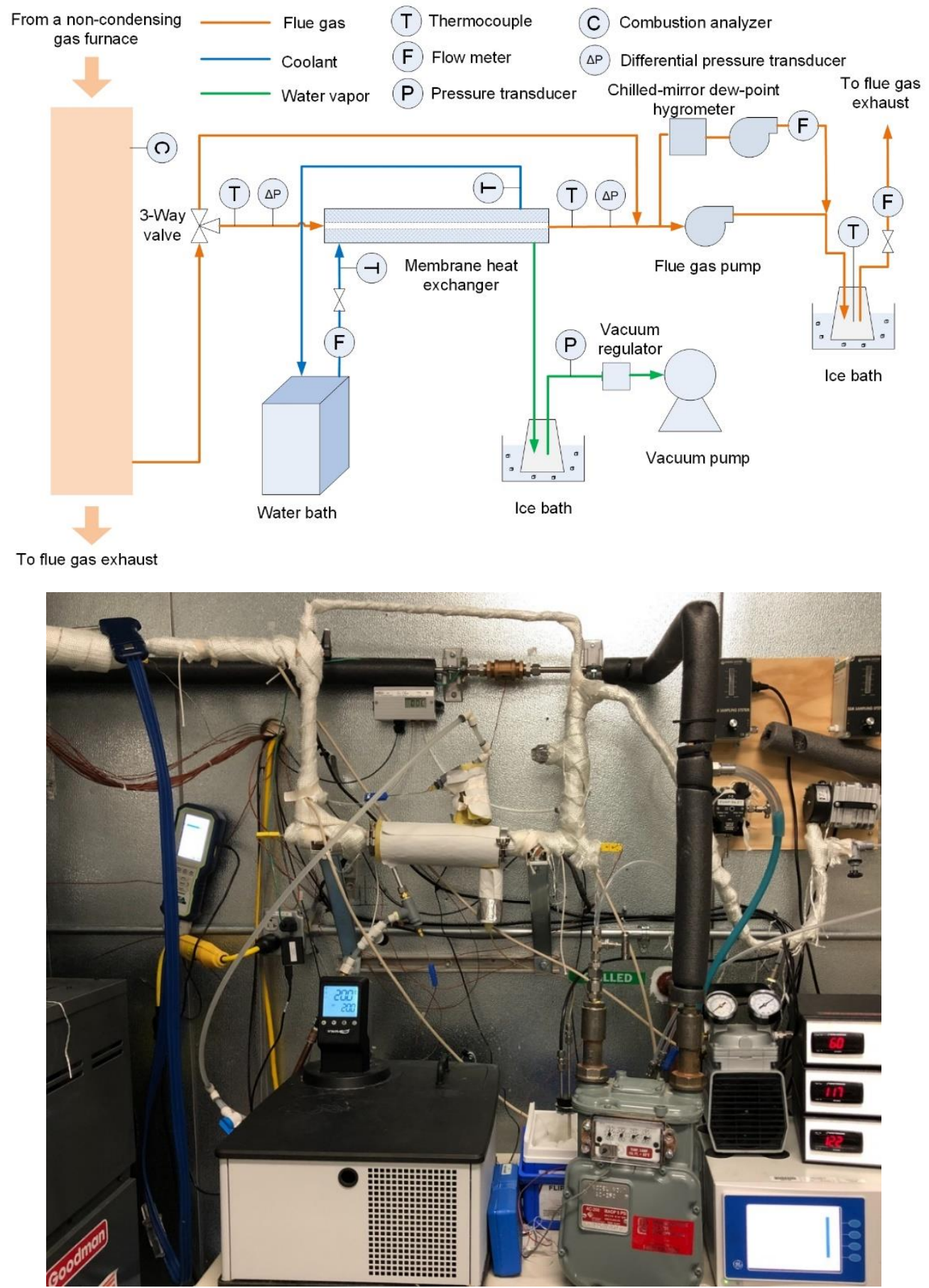

Figure A-1. Version 1 of the MHX testing system for the MHX. (top) Schematic and (bottom) photo. 
Test series 2: 9/23/2020-9/25/2020

The following modifications were made:

1. New stoppers and clamps were added to prevent flue gas leakage from the seals in the Erlenmeyer flask.

2. A metering valve on the cooling water loop was added to improve control of the cooling water.

3. A new humidity sensor on the supply air to the furnace combustion chamber was added to improve the calculation of the water content in the flue gas.

4. Thermocouple placement in the cooling loop was modified to ensure that the thermocouples were in the path of the flowing water and could not be affected by air bubbles. 


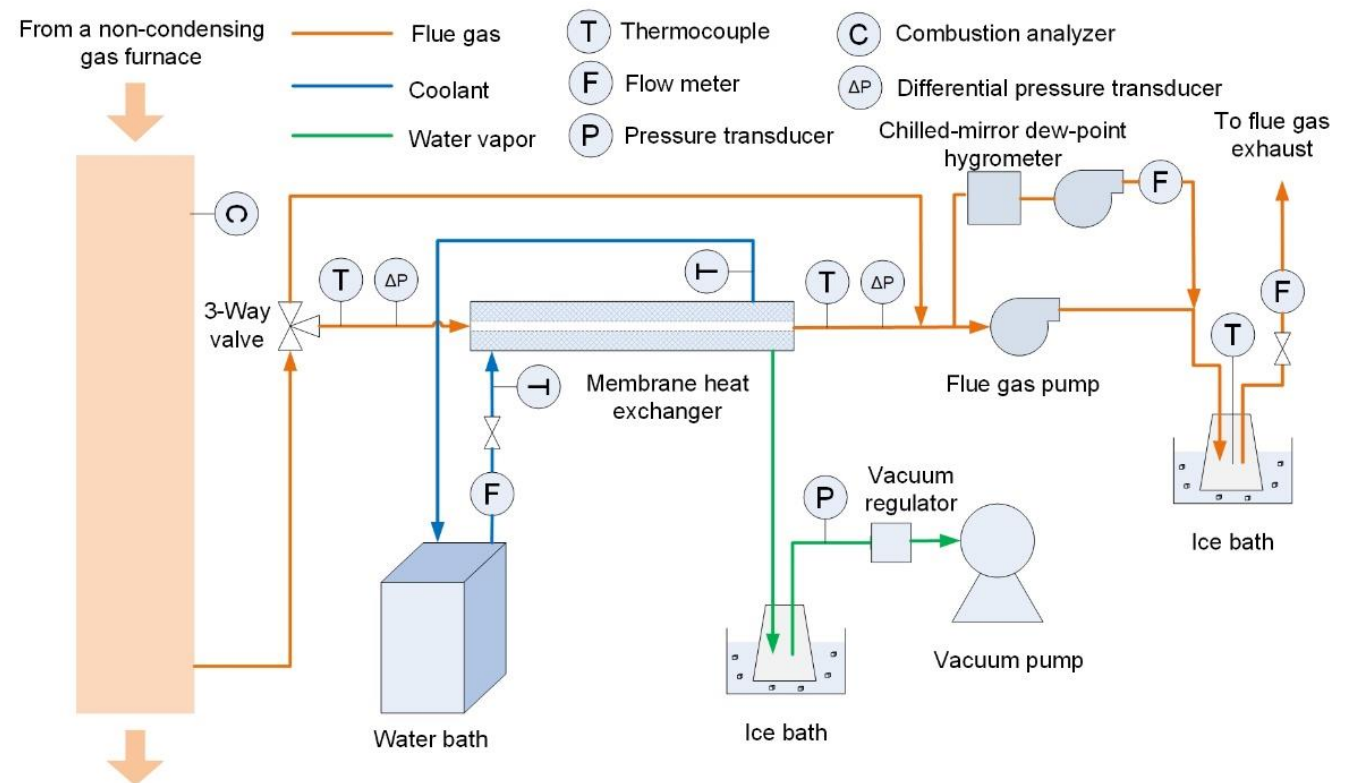

To flue gas exhaust

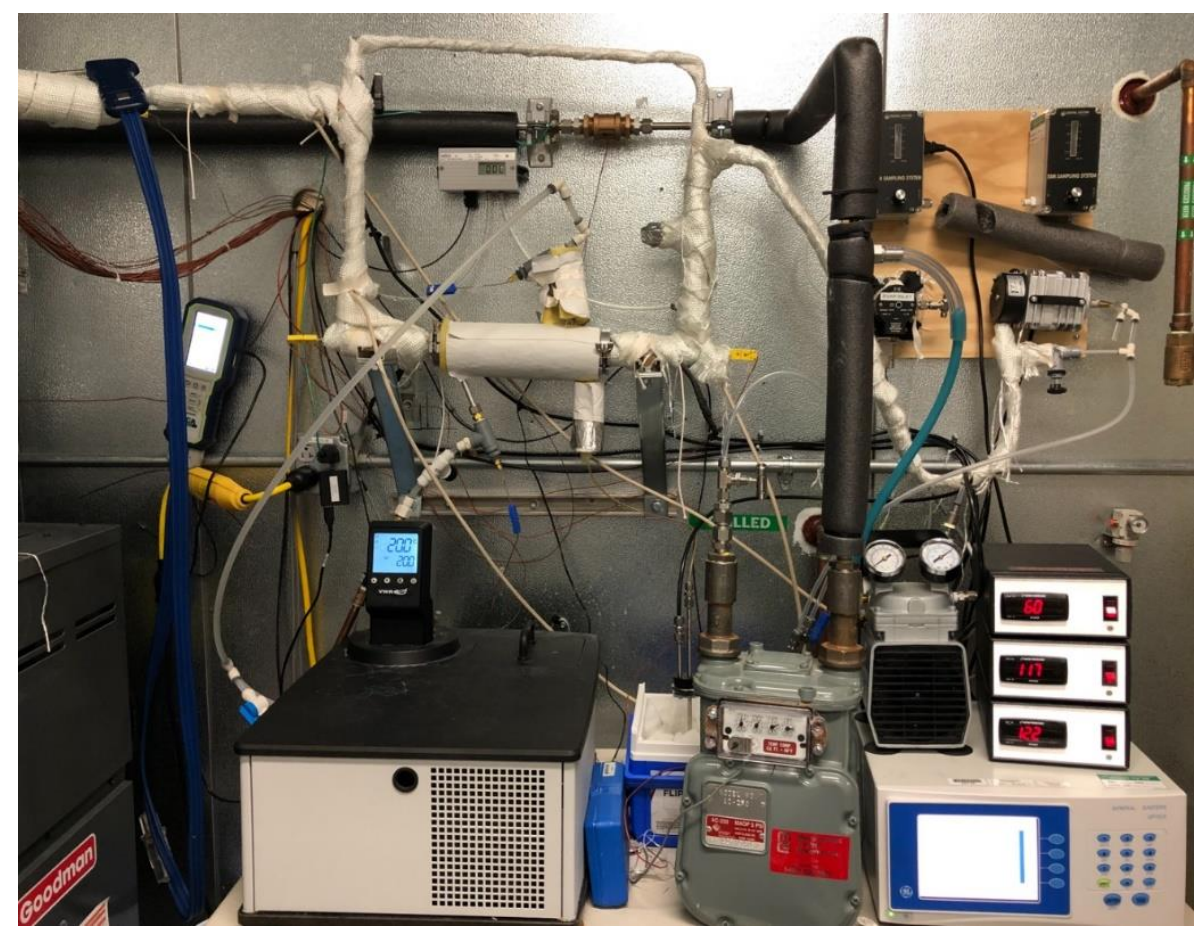

Figure A-2. Version 2 of the MHX testing system for the MHX. (top) Schematic and (bottom) photo. 
Test series 3: 2/18/2021-2/26/2021

The following modifications were made:

1. The air/gas pump was replaced with a larger air/gas pump.

2. A different data counter was added to collect the data from the flowmeter.

3. The 0.25 in. tubing was replaced with larger tubing $(0.325$ in. $)$ to reduce flue gas pressure drop and increase the flow.

4. The chilled-mirror dew-point hygrometer system was removed.

5. The ice bath that traps water vapor from flue gas exhaust was moved near to the outlet of the MHX to maximally collect the water vapor from flue gas exhaust. 


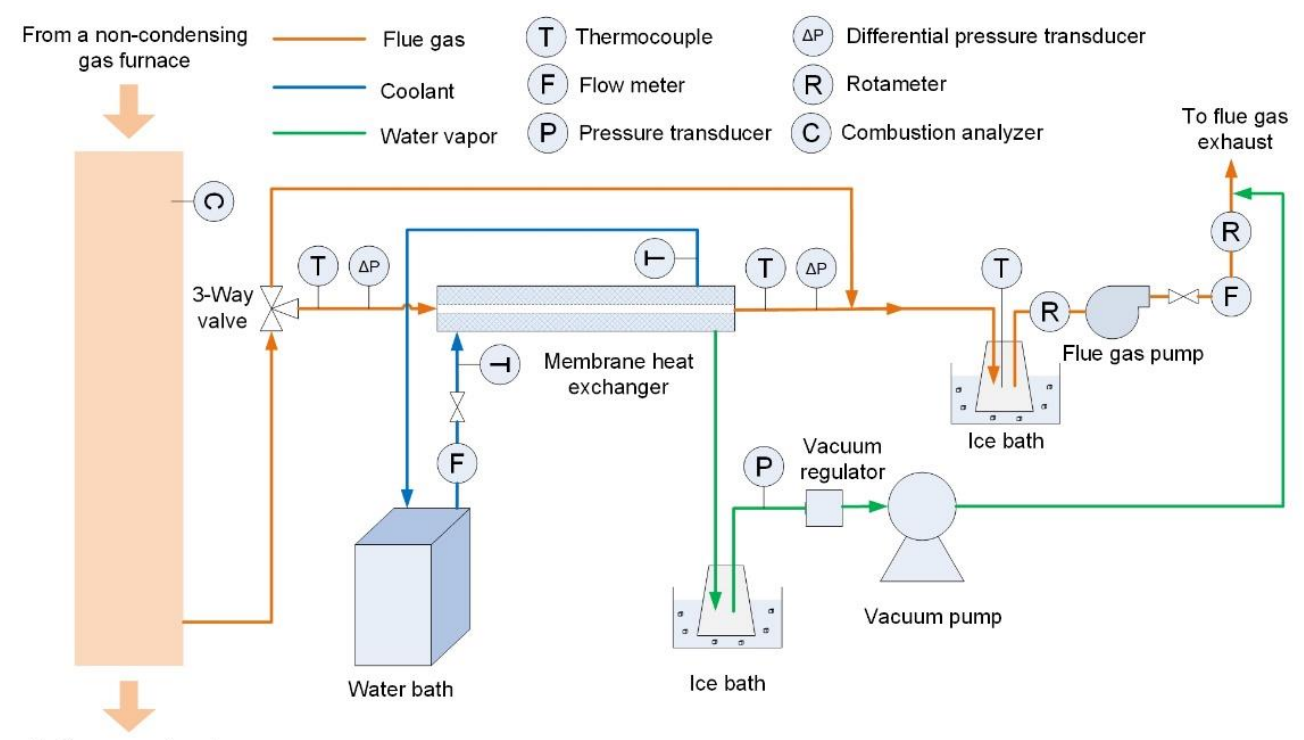

To flue gas exhaust

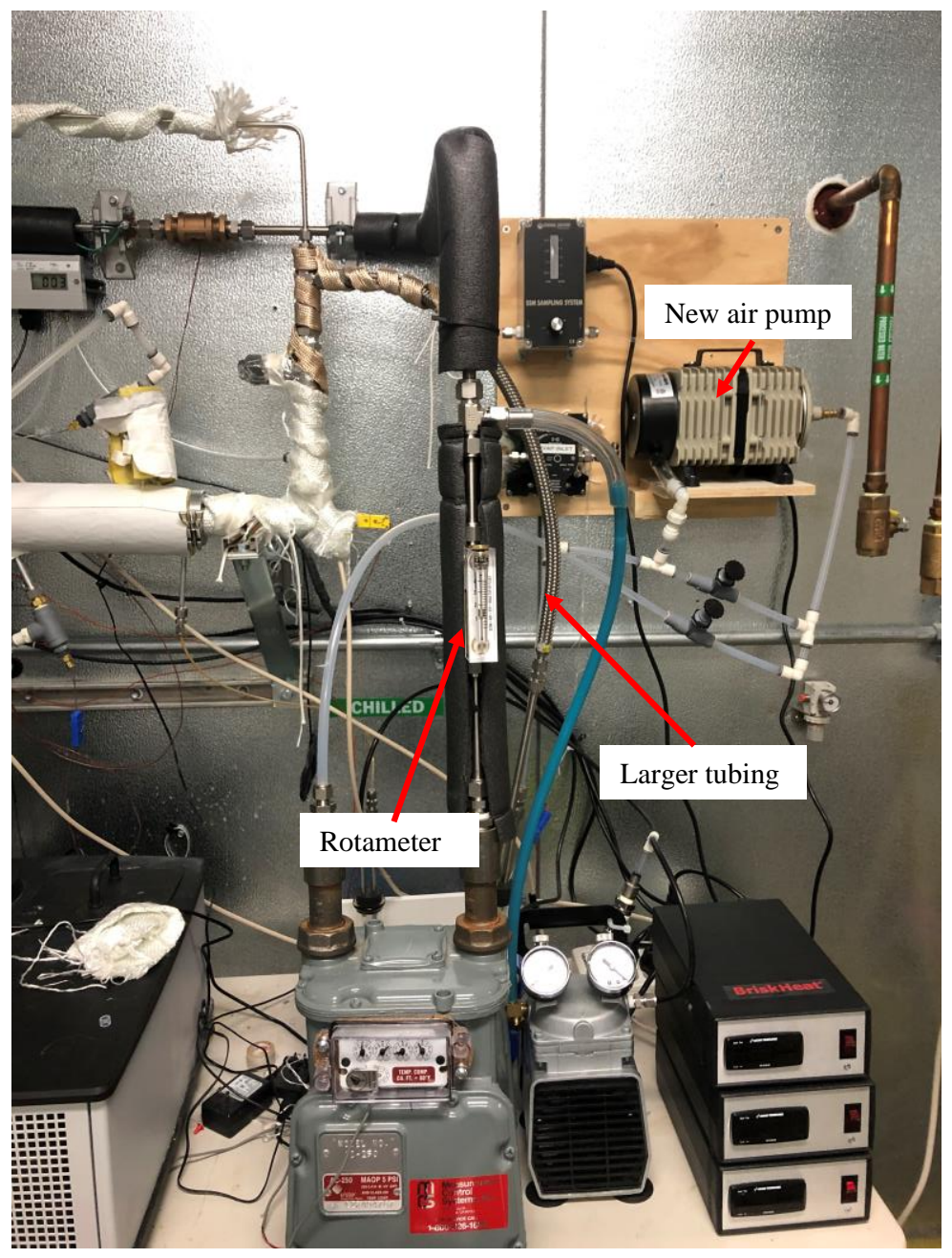

Figure A-3. Version 3 of the MHX testing system for the MHX. (top) Schematic and (bottom) photo. 
Test series 4: 4/22/2021-4/27/2021

The following modifications were made:

1. Heat tape was added to the MHX bypass line and other lines as necessary to prevent water from condensing in these sections.

2. The flowmeter of flue gas was moved to the upstream of the flue gas pump.

3. A second rotameter was added upstream of the flue gas pump to measure flue gas flow. 


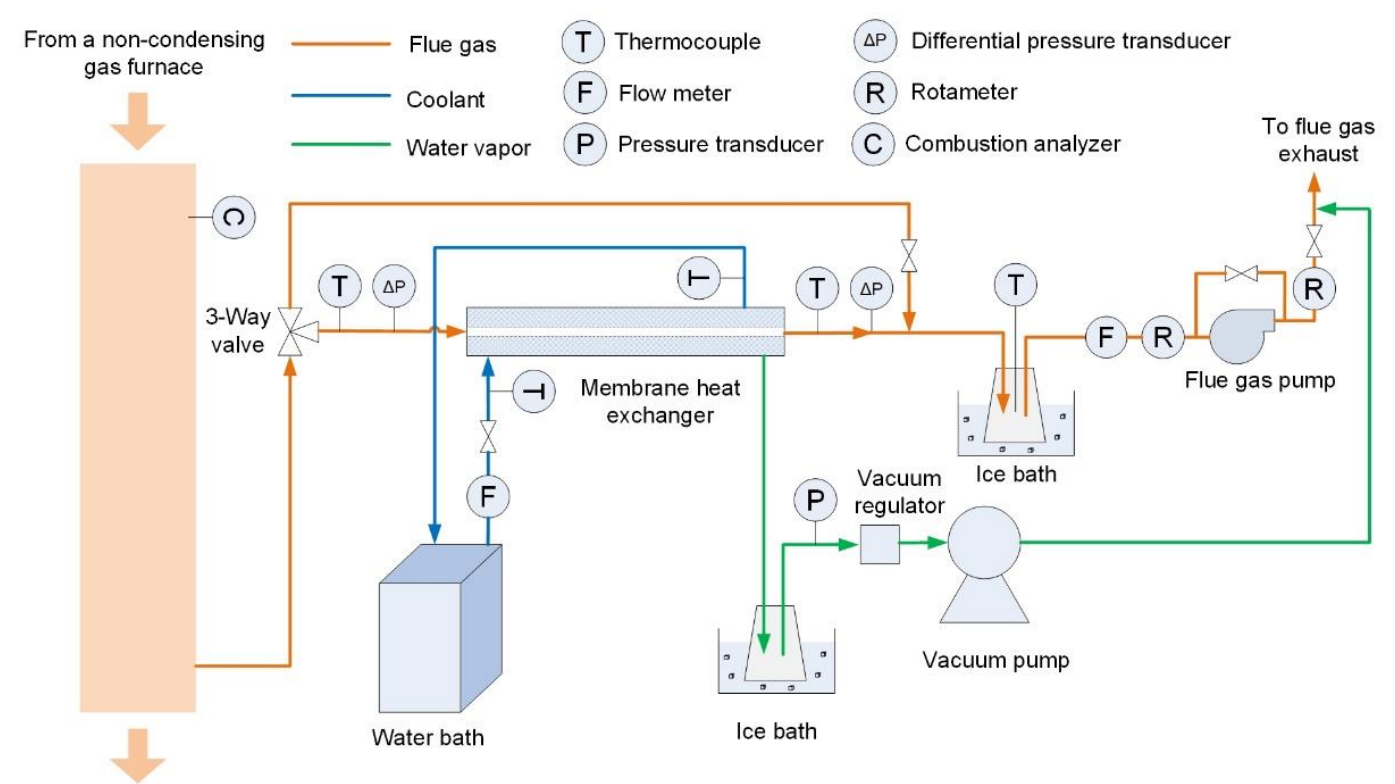

To flue gas exhaust

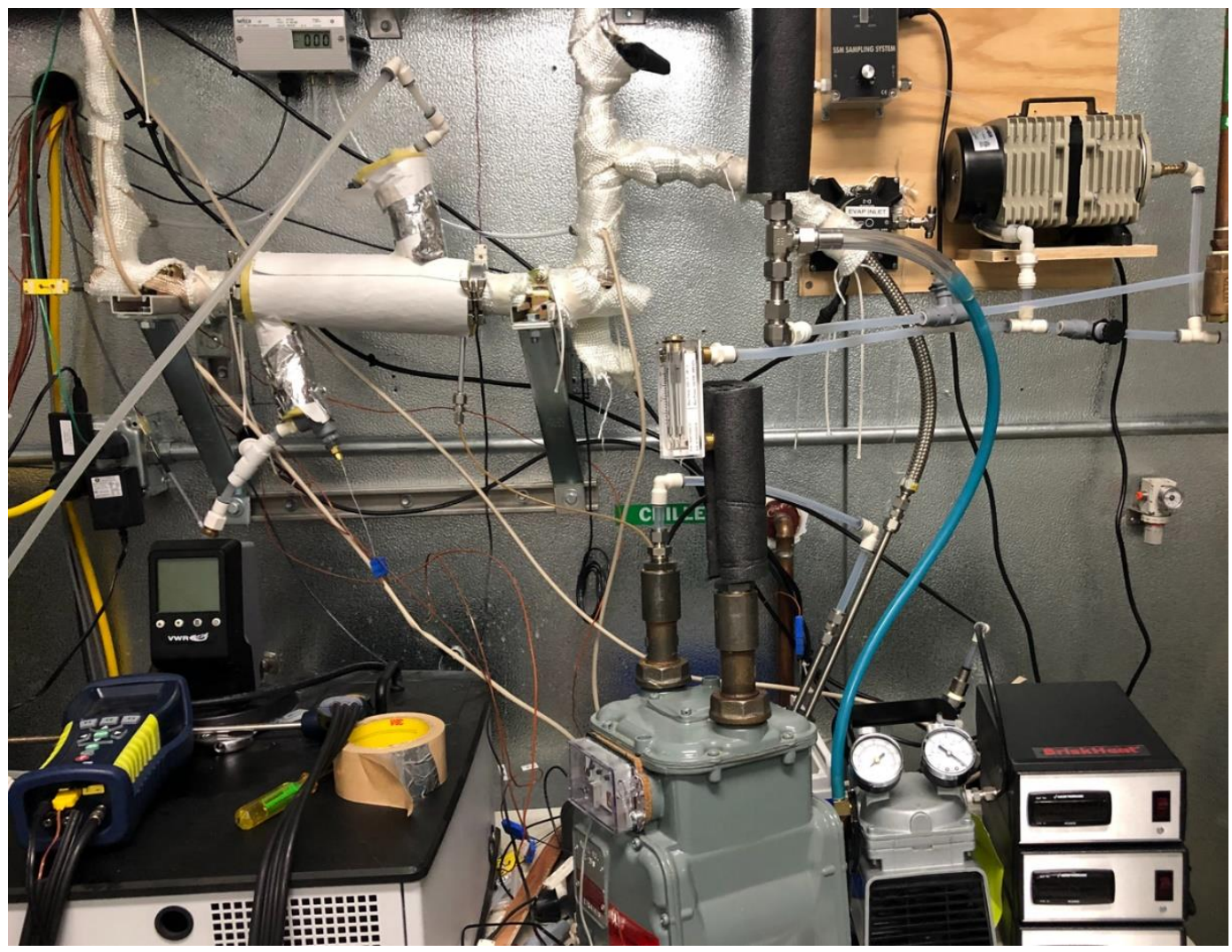

Figure A-4. Version 4 of the MHX testing system for the MHX. (top) Schematic and (bottom) photo. 


\section{APPENDIX B.}

\section{Example Prototype MHX Test Data}

The following figures show the progression of tests during the approximately $6 \mathrm{~h}$ taken to complete the first test each day. These data are for the first Series 4 test completed on April 27, 2021. Figure B-1 shows how four key temperatures change during the test. Figure B-2 shows the cooling water temperature. Figure B-3 shows the pressure created by the vacuum pump to pull the condensed water from the annular collection area of the MHX membrane holder. During the first 50-60 min, the flue gas flow and cooling water flow and temperature were adjusted until a steady state was achieved. At that point, the controllers for the heat trace tapes were turned on. The lines were heated before any flue gas was pumped through the MHX and the gas lines to prevent condensation in these areas of the test system. At about 75 min, the furnace was started. A few minutes later, the vacuum pump was turned on. This pressure change is evident at about $80 \mathrm{~min}$, as shown in Figure B-3. The water collection period of the test was started after the water exiting the MHX was consistent (i.e., when slugs of water were observed passing through the translucent Teflon lines). At $150 \mathrm{~min}$, the flasks were disconnected from the system, emptied, weighed, and reconnected to the system. This perturbation can be seen as a momentary drop in the temperature of the flue gas into the MHX, a drop in the temperature of the cooling water at the exit of the MHX, and an increase in the pressure, as shown in Figure B-3.

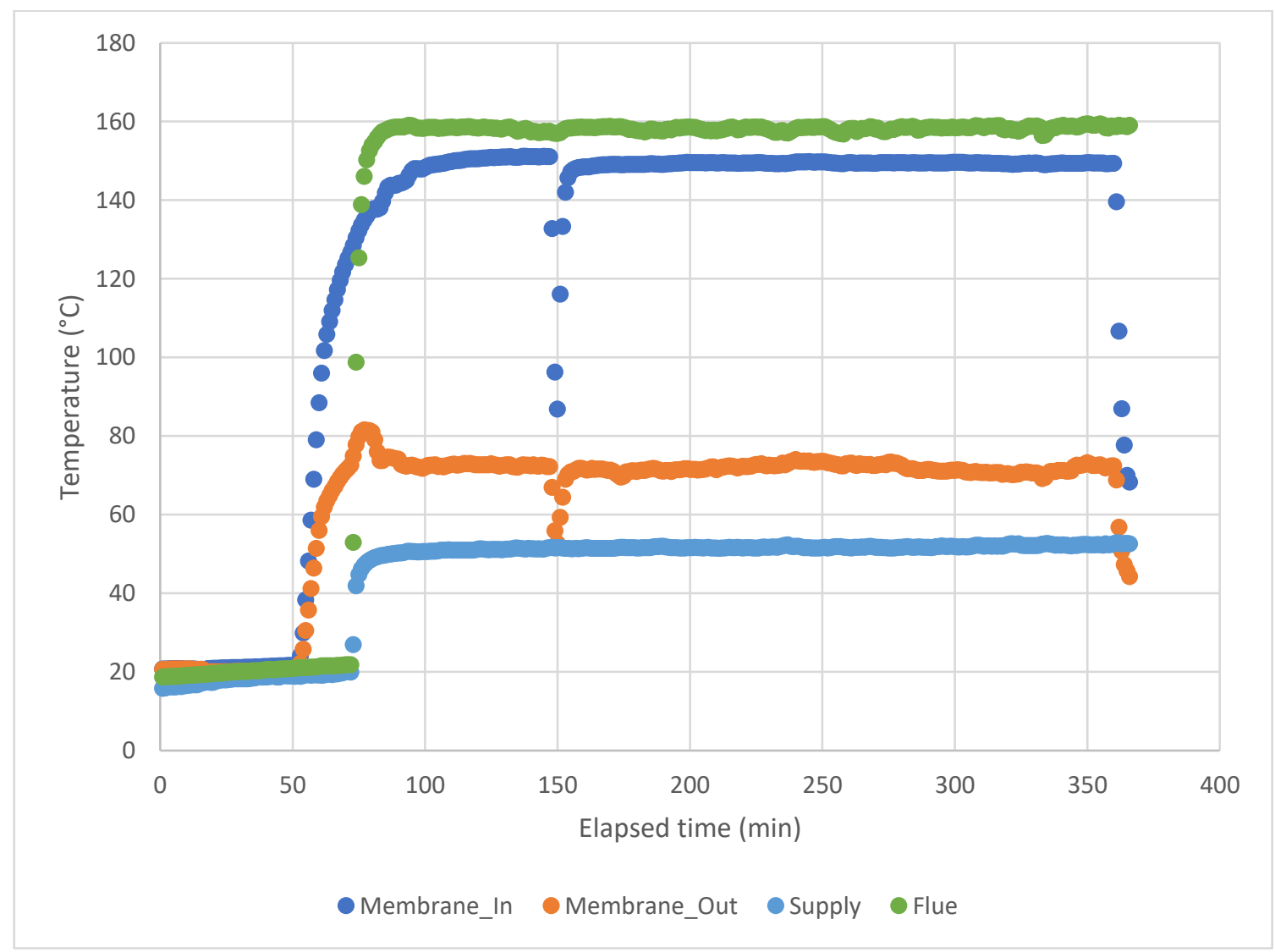

Figure B-1. Temperatures of flue gas entering and exiting the MHX, flue gas exiting the furnace, and supply air entering the furnace. 


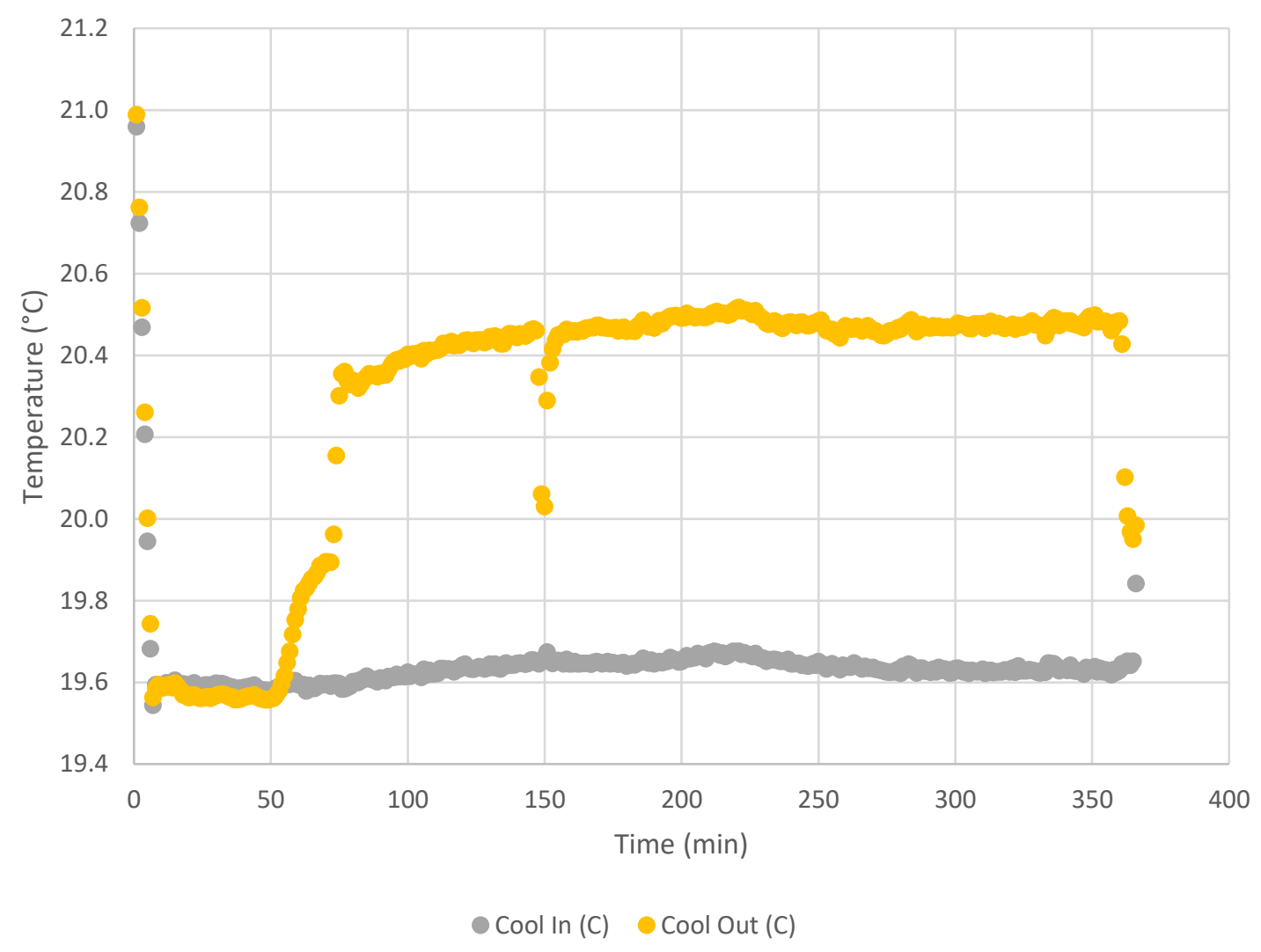

Figure B-2. Cooling water temperature entering and exiting the MHX. 


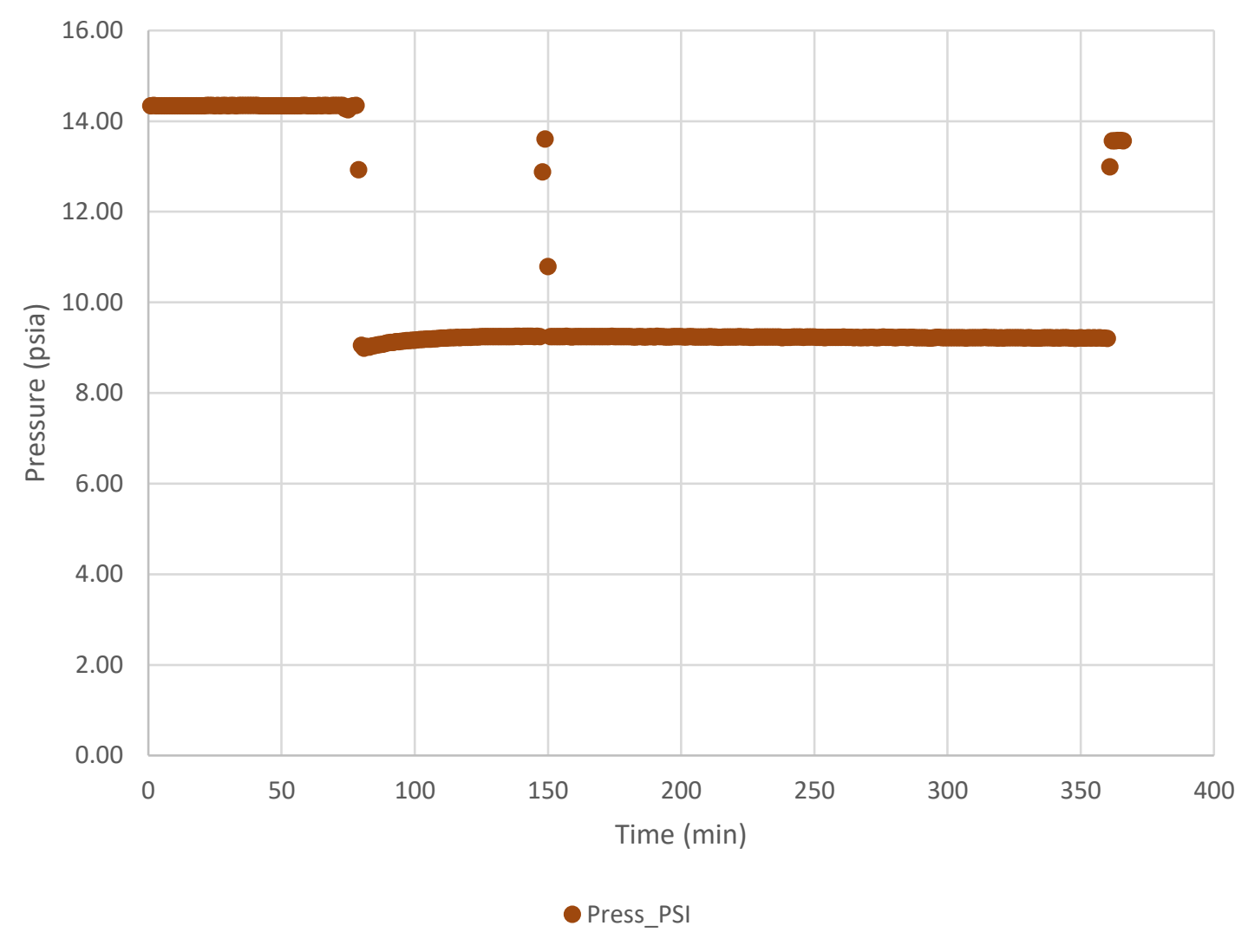

Figure B-3. Low side membrane pressure. Initial pressure is just over 14 psia or at atmospheric pressure. When the pump is on and flasks are in place, pressure is just over 9 psia. 


\section{APPENDIX C. \\ Comparison Between MHX Series 4 Data and Corrected Series 3 Data}

Between the Series 3 and Series 4 tests, air infiltration at the pump inlet was discovered in the pump employed for pulling the flue gas from the flue gas pipe of the furnace. This leak was confirmed by placing a flowmeter at the entrance and exit of the pump. The discrepancy in flow into and out of the pump prompted the relocating the pump to be placed downstream of the gas flowmeter. Although this modification did not prevent air from infiltrating the pump, it did prevent that infiltrated air from being measured by the gas flowmeter. The test using two flowmeters allowed the calculation of a correction factor that could be applied to the Series 3 data. The Series 3 tests were performed over a broader range of flue gas flow rates than the final Series 4 tests. Those data were corrected using the correction factor and plotted with the Series 4 data to show that this technology can be extended to a broader range of flows. Figures C-1 and C-2 show that when correcting for flow, the Series 3 and 4 data are in good agreement over the range tested.

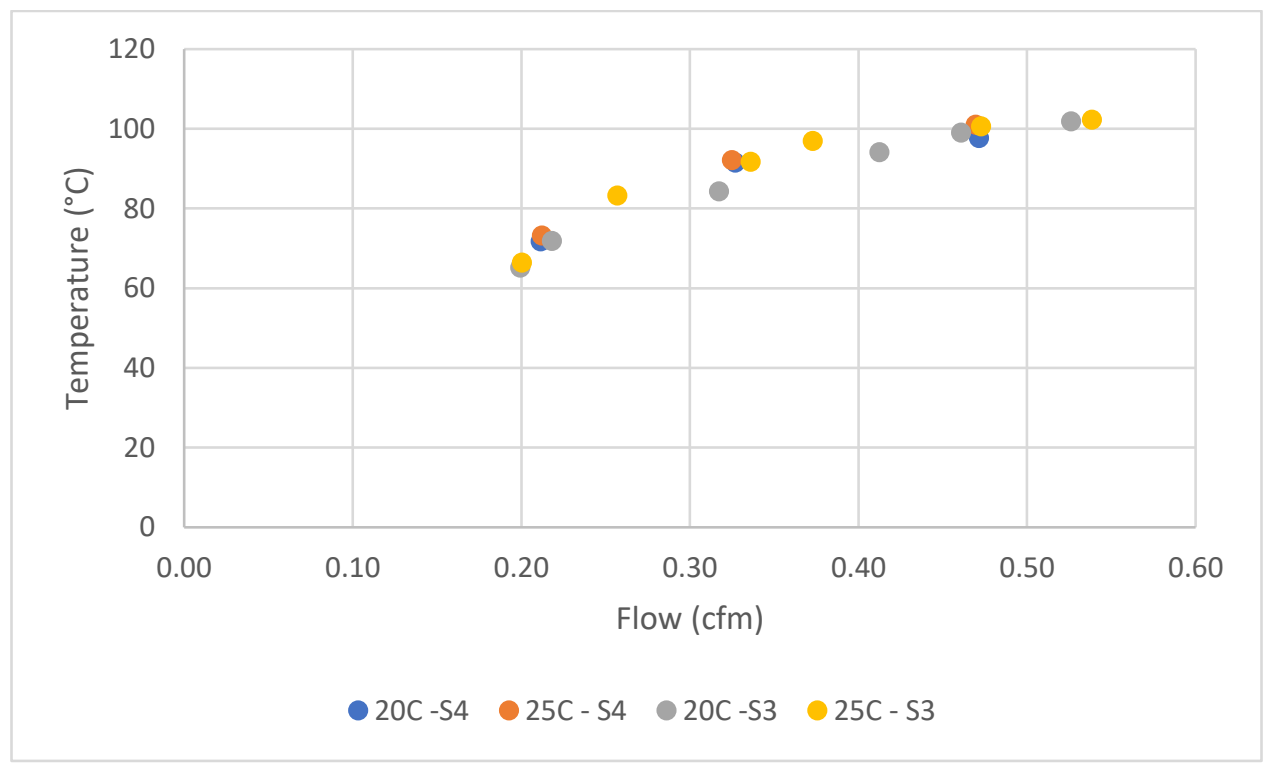

Figure C-1. MHX exit temperatures vs. flue gas flow of Series 3 data (corrected for flow) and Series 4 data. 


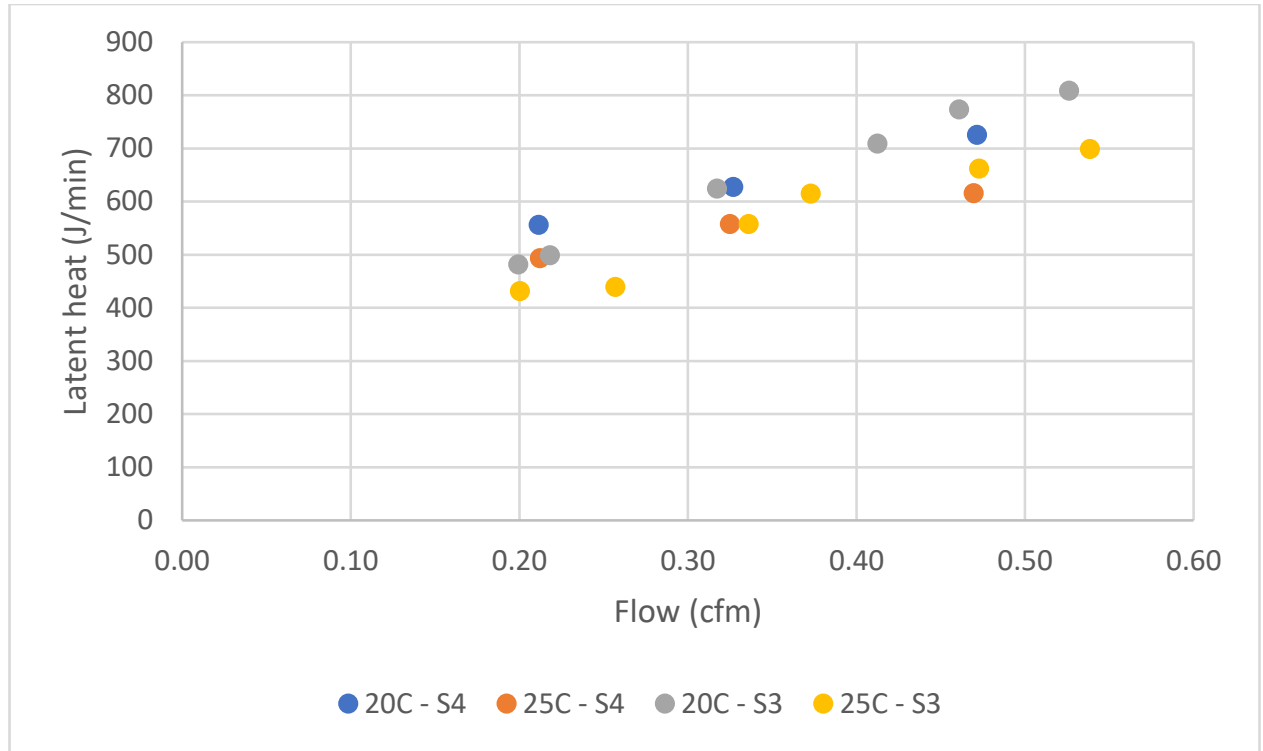

Figure C-2. Latent heat recovered vs. flue gas flow of Series 3 data (corrected for flow) and Series 4 data. 
